\title{
Triaromatic dinosteroids - Isomeric distributions and their geochemical significance
}

\author{
S.D. Killops ${ }^{\text {a, }}$, S. Zhang ${ }^{\mathrm{b}}$, E. Lichtfouse ${ }^{\mathrm{c}}$ \\ ${ }^{a}$ Applied Petroleum Technology AS, Oslo, Norway \\ ${ }^{\mathrm{b}}$ PetroChina Company Ltd, Beijing, China \\ ${ }^{\mathrm{c}}$ Aix-Marseille University, CNRS, IRD, INRA, Coll France, CEREGE, Aix en Provence, France. Email: eric.lichtfouse@gmail.com
}

\section{A R T I C L E I N F O}

\section{Keywords:}

Triaromatic dinosteroids

Triaromatic 28-nordinosteroids

A/B-ring methylated triaromatic steroids

Maturity

Biodegradation

Metamorphism

Depositional environment

Source age

\begin{abstract}
A B S T R A C T
The distribution of triaromatic dinosteroids in a range of oils and some source rock bitumens was determined by GC-MS selected ion monitoring and GC-MS-MS in order to investigate possible ambiguity in the observed distribution of isomers, including those related to maturation and alteration processes commonly affecting oil accumulations. The results confirm that the eight possible isomers for the triaromatic dinosteroids and their 28-nor equivalents (triaromatic 23,24-dimethylcholesteroids) in post-Paleozoic samples are consistently represented by six peaks on commonly used GC stationary phases, although the fifth eluting is broadened and probably represents a pair of isomers. The presence of a seventh, early eluting, triaromatic dinosteroid isomer occasionally encountered in $\mathrm{m} / \mathrm{z} 245$ mass chromatograms in the literature was not substantiated. Closely co-eluting compounds can give the seemingly misleading impression that one or two triaromatic dinosteroid isomers (including the last eluting) are present at low levels in pre-Mesozoic samples and in younger oils from dominantly higher plant sources, so care is required in inferring source age for such samples. The relative abundance and retention time pattern observed for the triaromatic dinosteroids is duplicated by their 28-nor analogues. Triaromatic dinosteroid isomer distributions vary little throughout the oil window, based on data from Norwegian North Sea oils representing a range of mean maturities. Overall abundance of the series seems to decline in a similar way to other biomarkers towards the end of the oil window. In source rock bitumen corresponding to maturities of $\leq 0.5 \%$ vitrinite reflectance, when diasterenes are still abundant, the second eluting triaromatic dinosteroid peak was enhanced and the fifth depleted in the limited set of samples studied (Late Jurassic marine shales from the Norwegian continental shelf). Both dinosteroid series appear particularly resistant towards biodegradation and metamorphism, with no obvious change in isomeric distributions compared to unaltered oil. As a consequence, their relative abundances, as represented by age parameters that ratio each series to their 24-ethyl counterparts, increase when alteration is severe. Lacustrine oils can be difficult to date because post-Paleozoic samples do not always contain detectable dinosteroids and, when they are present, they can vary significantly in abundance. Unambiguous age resolution at the Period level was not possible for the Triassic-Tertiary oils studied, neither could depositional environments be distinguished with confidence.
\end{abstract}

\section{Introduction}

Triaromatic dinosteroids and their 28-nor analogues (otherwise known as triaromatic 23,24-dimethylcholesteroids) have found a place among the geochemical tools for estimating the source age of an oil through their ability to distinguish Late Paleozoic from younger oils (Moldowan et al., 1996; Barbanti et al., 2011). An abundance of dinosteroids is usually characteristic of dinoflagellate contributions to Mesozoic and younger rocks, although other sources are possible (e.g. diatoms; Volkman et al., 1993). Some morphological affinity of acritarchs to dinoflagellates has been noted in Lower Cambrian strata, which led to the suggestion that ancient ancestors of dinoflagellates are responsible for the dinosteroids detected therein (Moldowan and Talyzina, 1998; Talyzina et al., 2000; Zhang et al., 2002a, b, 2010). However, the apparent absence of dinosteroid biomarkers from Carboniferous and Permian units and some early branches of core dinoflagellates has more recently led to the suggestion that, when the compounds are found in older sources, they likely originate from unrelated acritarchs that became extinct in the mid-Paleozoic (Janouškovek et al., 2017). Previous reports of Archean occurrences

\footnotetext{
* Corresponding author.
} 
(e.g. Brocks et al., 2003) are now considered doubtful due to contamination (French et al., 2015). Whether dinosteroids in pre-Mesozoic sediments are indigenous and represent either dinoflagellate ancestors or unrelated organisms or are even, at least in some examples, the result of contamination is likely to remain a matter of debate, as is the attribution of fossil remains (Fensome et al., 1999; Javaux and Marshal, 2006; Knoll et al., 2007; Penaud et al., 2018).

Chromatograms showing distributions of triaromatic dinosteroids or dinosteranes in Paleozoic samples are sparse in the literature. It is not always easy to determine whether their presence has been based upon the recognisable distribution of all isomers, particularly where abundances approach detection limits. For example, in Huqf rocks and associated oils analysed by Grosjean et al. (2009), 3ß-methyl-24-ethylcholestanes were the dominant compounds in $\mathrm{m} / \mathrm{z} 414 \rightarrow 231$ chromatograms, and if any 4-methylsteranes were present, they were only trace constituents in MRM chromatograms from alkane fractions. At such levels dinosteranes are difficult to identify, because cross-talk signals from ubiquitous compounds, such as hopanes, can give rise to low abundance peaks in the same region of these chromatograms (Love, G. D., pers. commun.). However, convincing evidence of traces of dinosteranes in $m / z 414 \rightarrow 231$ and $414 \rightarrow 98$ chromatograms from isolated Early Cambrian acritarchs from Estonia has been presented by Talyzina et al. (2000). The high values for ratios of combined triaromatic dinosteroid isomers to either 3- or 4-methyl-24-ethylcholesteroids in $\mathrm{m} /$ z 245 mass chromatograms reported by Moldowan et al. (1996) in a few Cambrian-Devonian samples suggests absolute abundance can be sufficiently high to identify all of the isomers. Such examples are seemingly rare, though. Among the source rocks analysed by Barbanti et al. (2011), mostly zero values were recorded for the $\Sigma$ (triaromatic dinosteroids)/ [triaromatic (20R)-24-ethylcholesteroid] ratio, and in only a pair of Ordovician samples were both triaromatic dinosteroids and their 28-nor counterparts detected.

Triaromatic dinosteroids and their 28-nor analogues share isomeric centres at C-20, C-23 and C-24 (Fig. 1), resulting in potentially eight stereoisomers. A synthetic scheme for the $20 \mathrm{R}$ triaromatic dinosteroids has been reported (Shetty et al., 1994), but a proposed subsequent article, in which identification of the compounds in petroleum by GC-MS co-elution experiments was to be reported, unfortunately was never published. Only six peaks have been positively identified as 28nordinosteroid isomers in $\mathrm{m} / \mathrm{z} 231$ mass chromatograms of geological samples and a synthetic standard (Barbanti et al., 2011). Similarly, six peaks are routinely identified as triaromatic dinosteroids in $m / z 245$ mass chromatograms. Two of the possible eight isomers in both series may not be biosynthesised or may not be resolved from others on commonly used gas chromatography-mass spectrometry (GC-MS) stationary phases.

A number of articles have appeared in the literature in which a seventh, early eluting, small peak in $m / z 245$ mass chromatograms has been attributed to a triaromatic dinosteroid isomer (see Fig. 2). Most of these reports have focussed on the Cambrian $\mathrm{O} 1$ source unit in the Tarim Basin and associated oils, particularly the Tadong-2 oil (e.g. Zhang et al., 2000; Ma et al., 2008; Li et al., 2012; Song et al., 2015; Huang et al.,
2016; Bao et al., 2018). Examples from some other locations include Paleogene lacustrine shales/mudstones from the Bohai Basin (Wang et al., 2008), a Carboniferous oil from the Junggar Basin (Xu et al., 2018) and, outside China, Niger Delta oils and source rocks (Ogbesejana, 2018; Ogbesejana et al., 2018), mid-Cretaceous Oceanic Anoxic Event deposits from the Vocontian Basin in southeast France (Ando et al., 2017) and oils attributed to Darfur Gp sources in the Muglad Basin, Sudan and South Sudan (Xiao et al., 2019). In these publications, triaromatic dinosteroid and other methyl triaromatic steroid identifications appear to be based on the analyses performed at Stanford University reported by Zhang et al. (2000). These articles also share a couple of misidentifications of 3-methyl and 4-methyl triaromatic steroids.

The aim of the current study was to investigate triaromatic dinosteroid peak distributions in a range of oils for any statistically significant variations that may affect identification of the compounds and their geochemical application in relation to source age, depositional environment and maturity, and in-reservoir alteration by metamorphism or biodegradation. An integral aspect was determining whether there is definitive evidence of a seventh triaromatic dinosteroid peak in $\mathrm{m} / z 245$ mass chromatograms of at least some oils, including the Tadong-2 oil. Variation in isomer distributions was examined for three sets of oils with reasonably well resolved and abundant triaromatic dinosteroids in order to minimise contributions from co-eluants. They included replicates of a standard oil, to investigate analytical variance, a suite of Jurassic sourced North Sea oils and a collection of oils from around the world of varying source age and depositional environment. As well as selected ion recording (SIR) by GC-MS, GC-MS-MS analyses were also employed where more detailed information on aromatic steroid distributions was required.

\section{Methods and Samples}

Washed and milled cuttings ( $\sim 10 \mathrm{~g})$ were extracted by reflux $(\sim 1 \mathrm{~h})$ in dichloromethane with $7 \%$ (vol/vol) methanol $(\sim 80 \mathrm{~mL})$ using a Soxtec (Tecator) instrument, followed by rinsing $(2 \mathrm{~h})$ with the solvent. Elemental $\mathrm{S}$ was removed by addition of freshly activated $\mathrm{Cu}$ blades. Extracts and oils were then subjected to the same procedures. Fractionation employed a medium pressure liquid chromatography (MPLC) system, as described by Radke et al. (1980), which included a Kieselgel 100 pre-column and LiChroprep Si60 main column. Approximately 30 $\mathrm{mg}$ of deasphaltened extract, diluted to $1 \mathrm{~mL}$ in $n$-hexane, was injected into the MPLC system to obtain a saturates fraction upon elution with $n$ hexane and an aromatics fraction by back-flushing the main column with $n$-hexane. All fractions were concentrated to $\sim 1 \mathrm{~mL}$ using an automated evaporation system (Turbovap).

High resolution (HR), GC-MS-SIR of total hydrocarbon fractions employed a Thermo Scientific DFS magnetic sector instrument, tuned to a resolution of 3000 . A $60 \mathrm{~m}$ CP-Sil-5 CB-MS column with an i.d. of 0.25 $\mathrm{mm}$ and a film thickness of $0.25 \mu \mathrm{m}$ was used with a temperature programme of $50{ }^{\circ} \mathrm{C}\left(1 \mathrm{~min}\right.$. isothermal) to $120^{\circ} \mathrm{C}$ at $20^{\circ} / \mathrm{min}$. and then at $2^{\circ} / \mathrm{min}$. to $320^{\circ} \mathrm{C}(20 \mathrm{~min}$. isothermal). GC-MS-MS analyses of aromatic fractions were performed on a Thermo Scientific Quantum 9000

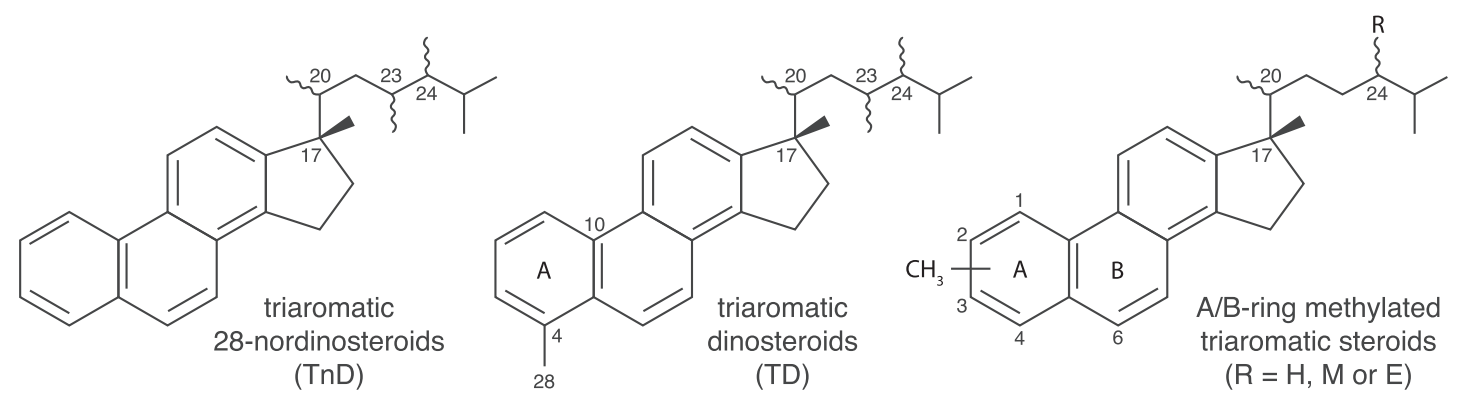

Fig. 1. Structures of methylated triaromatic steroids. Triaromatic dinosteroids are represented by TD1-TD6, their 28-nor analogues by TnD1-TnD6. 
(a) Tarim Basin - Tadong-2

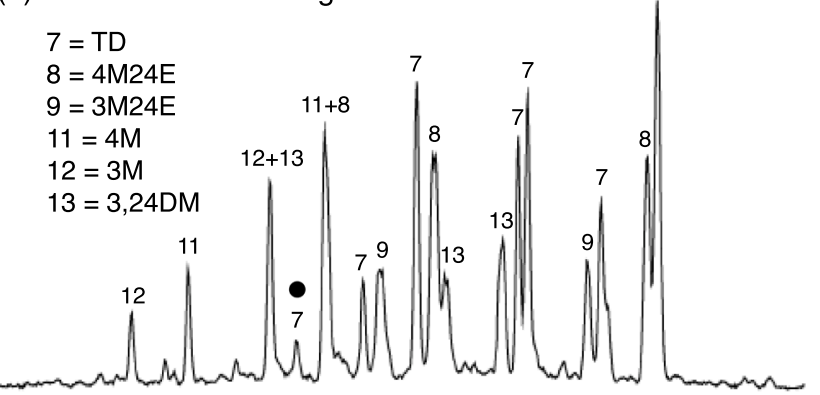

(b) Niger Delta
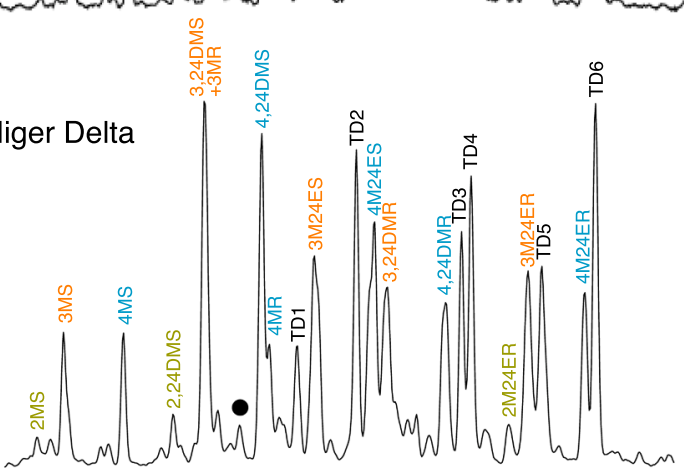

(c) Norwegian N Sea - NSO-1
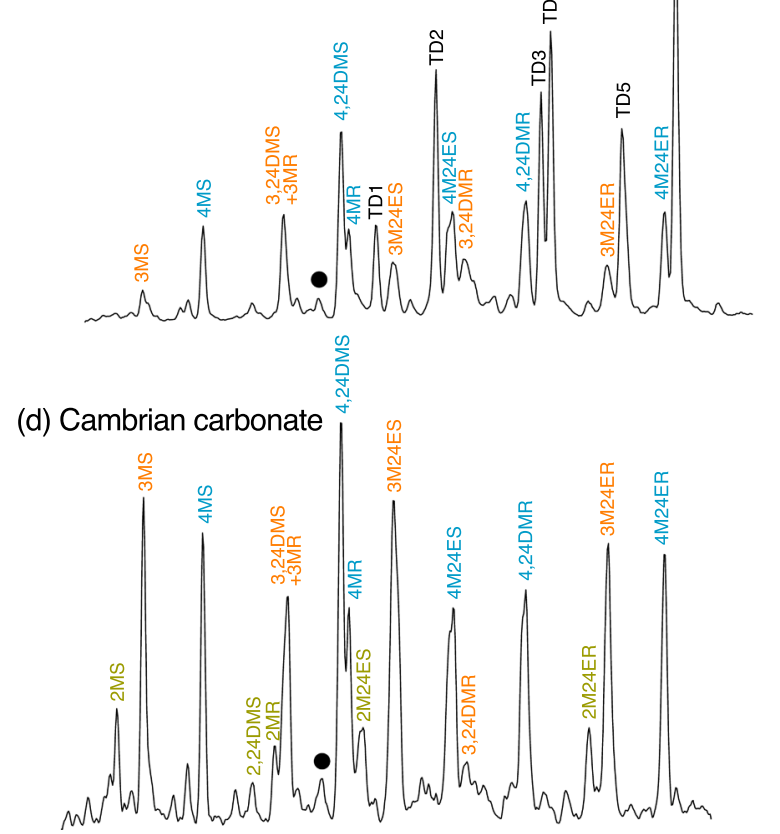

Fig. 2. Examples of purported occurrence of early eluting, seventh triaromatic dinosteroid peak (•) in oils from (a) Tarim Basin (Tadong-2), (b) Niger Delta, (c) North Sea (NSO-1 standard) and (d) Oman (Cambrian carbonate). See Table 2 for compound identifications. Tadong- $2 \mathrm{~m} / \mathrm{z} 245$ chromatogram (a) is from Bao et al. (2018), with peak labelling after Zhang et al. (2000; configuration at C-20 not given). Chromatograms (b)-(d) are $m / z 245.13$ responses from HR-GC-MSSIR analyses of total hydrocarbons.

quadrupole instrument, tuned to unit $m / z$ resolution, with argon as the collision gas at an energy of $15 \mathrm{~V}$. The GC column was as above, but with a temperature programme of $50{ }^{\circ} \mathrm{C}(1 \mathrm{~min}$. isothermal $)$ to $115^{\circ} \mathrm{C}$ at $20^{\circ}$ / min. and then at $2^{\circ} / \mathrm{min}$. to $325^{\circ} \mathrm{C}(30 \mathrm{~min}$. isothermal).

Oil samples are described in Appendices 1-3. Analyses spanned the same time interval for all three sets (2005-19). Data for the standard oil
(NSO-1) replicates were from the same analysis batches as the North Sea oils (for details of NSO-1 see NIGOGA, 2000).

\section{Results and discussion}

\subsection{Isomer identification}

The first step of examining how isomer distributions may vary among the triaromatic dinosteroids in $\mathrm{m} / z 245$ mass chromatograms was to investigate the possible existence of an early eluting, seventh peak in a sample of the Tadong-2 oil. The corresponding peak (•, Fig. 2) was observed in that oil and a range of others, examples of which are shown in Fig. 2 and include an Omani Cambrian oil for which there is no evidence of the usual six major triaromatic dinosteroid peaks (TD1-TD6).

The use of $100 \%$ methylpolysiloxane stationary phase in this study appears to have little influence on the relative retention times of A/Bring methylated triaromatic steroids in general, when compared to the $5 \%$-phenyl-methylsilicone more often reported, other than slightly better resolution of the (20S)-4,24-dimethyl- and (20R)-4-methylcholesteroids (4,24DMS and 4MR, respectively, Fig. 2; see Table 1 for abbreviations). Similar chromatographic behaviour has been reported using another $100 \%$-methylpolysiloxane stationary phase formulation, SE-30 (Lichtfouse, 1989). In most reports of the Tarim Tadong-2 oil, 4,24DMR has been misidentified as a 3,24DM isomer (latest eluting of the three peaks labelled 13, Fig. 2a) and 4,24DMS as a 4M24E isomer (earliest eluting of the three peaks labelled 8, Fig. 2a). Revised

Table 1

Key to peak labelling in chromatograms.

\begin{tabular}{|c|c|}
\hline \multicolumn{2}{|c|}{ A-ring methylated triaromatic steroids } \\
\hline \multicolumn{2}{|l|}{$\begin{array}{l}m / z 245 \text { SIR \& MS-MS } m / z \\
\quad M \longrightarrow 245\end{array}$} \\
\hline 2M21, 3М21, 4M21, 6M21 & 2-/3-/4-/6-methyl C21 triaromatic steroids \\
\hline 2M22, 3М22, 4M22, 6M22 & 2-/3-/4-/6-methyl C22 triaromatic steroids \\
\hline 2M23, 3M23, 4M23, 6M23 & 2-/3-/4-/6-methyl C23 triaromatic steroids \\
\hline 2MS/R, 3MS/R, 4MS/R & triaromatic 2-/3-/4-methylcholesteroids $20 \mathrm{~S} / \mathrm{R}$ \\
\hline $\begin{array}{l}\text { 2,24DMS/R, 3,24DMS/R, } \\
\text { 4,24DMS/R }\end{array}$ & $\begin{array}{l}\text { triaromatic } 2-/ 3-/ 4 \text {-methyl-24- } \\
\text { methylcholesteroids } 20 \text { S/R }\end{array}$ \\
\hline $\begin{array}{l}\text { 2M24ES/R, 3M24ES/R, } \\
\text { 4M24ES/R }\end{array}$ & $\begin{array}{l}\text { triaromatic 2-/3-/4-methyl-24- } \\
\text { ethylcholesteroids } 20 \mathrm{~S} / \mathrm{R}\end{array}$ \\
\hline $\begin{array}{l}\text { TD1-TD6 } \\
\text { triaromatic steroids }\end{array}$ & triaromatic dinosteroids \\
\hline \multicolumn{2}{|l|}{$\begin{array}{l}m / z 231 \text { SIR \& MS-MS } m / z \\
\quad M \longrightarrow 231\end{array}$} \\
\hline 21,21 & C21 \& C22 triaromatic steroids \\
\hline $26 S / R$ & C26 triaromatic steroids $20 \mathrm{~S} / \mathrm{R}$ \\
\hline 27S/R & C27 triaromatic steroids $20 \mathrm{~S} / \mathrm{R}$ \\
\hline 28S/R & C28 triaromatic steroids $20 \mathrm{~S} / \mathrm{R}$ \\
\hline TnD1-TnD6 & triaromatic 28-nor-dinosteroids \\
\hline \multicolumn{2}{|l|}{ diasterenes } \\
\hline \multicolumn{2}{|l|}{$m / z 257$ SIR } \\
\hline 29d $\alpha 13$ en 17 & $10 \alpha$-24-ethyl-diacholest-13,17-ene $20 \mathrm{~S}+20 \mathrm{R}$ \\
\hline \multicolumn{2}{|l|}{ steranes } \\
\hline \multicolumn{2}{|l|}{$m / z 217$ SIR } \\
\hline $21 \beta \beta, 22 \beta \beta$ & C21 \& C22 $5 \alpha, 14 \beta, 17 \beta$ steranes \\
\hline $21 \mathrm{~d} \beta, 22 \mathrm{~d} \beta$ & C21 \& C22 13 $\beta, 17 \alpha$ diasteranes \\
\hline $27 \mathrm{~d} \beta \mathrm{S} / \mathrm{R}$ & $13 \beta, 17 \alpha$-diacholestane $20 \mathrm{~S} / \mathrm{R}$ \\
\hline 29aaS/R & $5 \alpha, 14 \alpha, 17 \alpha$-24-ethylcholestane $20 \mathrm{~S} / \mathrm{R}$ \\
\hline \multicolumn{2}{|l|}{ 4-methylsteranes } \\
\hline \multicolumn{2}{|l|}{ MS-MS $m / z$ 414 $\longrightarrow 231$} \\
\hline $3 \mathrm{M} \alpha \alpha \mathrm{S} / \mathrm{R}$ & 3-methyl-24-ethyl-14 $\alpha, 17 \alpha$-cholestane $20 \mathrm{~S} / \mathrm{R}$ \\
\hline $3 \mathrm{M} \beta \beta \mathrm{S} / \mathrm{R}$ & 3-methyl-24-ethyl-14 $\beta, 17 \beta$-cholestane $20 \mathrm{~S} / \mathrm{R}$ \\
\hline $4 \mathrm{M} \alpha \alpha \mathrm{R}$ & 4-methyl-24-ethyl-14 $\alpha, 17 \alpha$-(20R)-cholestane \\
\hline $\begin{array}{l}\text { DSS, DSR, DRR, DRS } \\
\text { cheilanthanes } \\
\text { m/z } 191 \text { SIR }\end{array}$ & dinosteranes S/R at C-23 \& C-24 \\
\hline $23 \mathrm{C}$ & C23 $13 \beta, 14 \alpha$-cheilanthane \\
\hline \multicolumn{2}{|l|}{ hopanes } \\
\hline \multicolumn{2}{|l|}{$m / z 191$ SIR } \\
\hline $27 \mathrm{~N}, 29 \mathrm{~N}, 30 \mathrm{~N}$ & C27, C29 \& C30 18 $\alpha$-neohopanes \\
\hline $27 \alpha \beta, 29 \alpha \beta, 30 \alpha \beta$ & C27, C29 \& C30 17 $\alpha$-hopanes \\
\hline $30 \mathrm{~d}$ & $17 \alpha$-diahopane \\
\hline
\end{tabular}


identifications are based on the GC-MS-MS analyses described below and comparison with the literature (e.g. Fig. 5 of Brocks et al., 2015).

GC-MS-MS analysis of the Tadong-2 oil did not support a $\mathrm{C}_{29}$ A-ring methylated triaromatic steroid being responsible for peak $\bullet$. A corresponding signal in the $m / z 372 \rightarrow 245$ transition in Fig. 3 suggests that a $\mathrm{C}_{28}$ analogue makes at least some contribution. The same observation was made during GC-MS-MS analyses of other samples. It is possible that peak • represents the (20S)-6,24-dimethylcholesteroid (6,24DMS), based on the elution order of methylated triaromatic steroids by Lichtfouse (1989). For a given C-number and C-20 configuration, structural variability among the regular triaromatic steroids is limited to the position of the methyl group on the A or B ring, analogous to the isomers of methylphenanthrene. The conventional numbering systems are different for these two compound groups (Fig. 4b), so the observed relative retention times for methylphenanthrenes of $3<2<9<1$ equates to $2<$ $3<64$ for the triaromatic methylsteroids. This order has been confirmed for $\mathrm{C}_{21}$ components by co-elution with authentic standards, although the 2- and 3-methyl isomers were not well resolved (Fig. 4a; Lichtfouse, 1989). The longer column used in the present study has resulted in improved resolution (Fig. 4c). 6,24DMS would be expected to elute in the region of peak $\bullet$, although the much lower abundance of other, resolved 6-methyl $\mathrm{C}_{27}-\mathrm{C}_{29}$ compounds suggests that an alternative, unidentified compound may be responsible (a meaningful mass spectrum could not be obtained because of co-elution problems). One possibility is a 1-methyl triaromatic steroid. These compounds have yet to be positively identified in oils, but are unlikely to be more than trace components, given the low abundance of the structurally equivalent 4MP, which results from the elevated steric strain in this isomer (Garrigues and Ewald, 1983). Because 4MP co-elutes with 9MP on $100 \%$ methyl and 5/95\% phenyl/methyl silicone stationary phases, it is
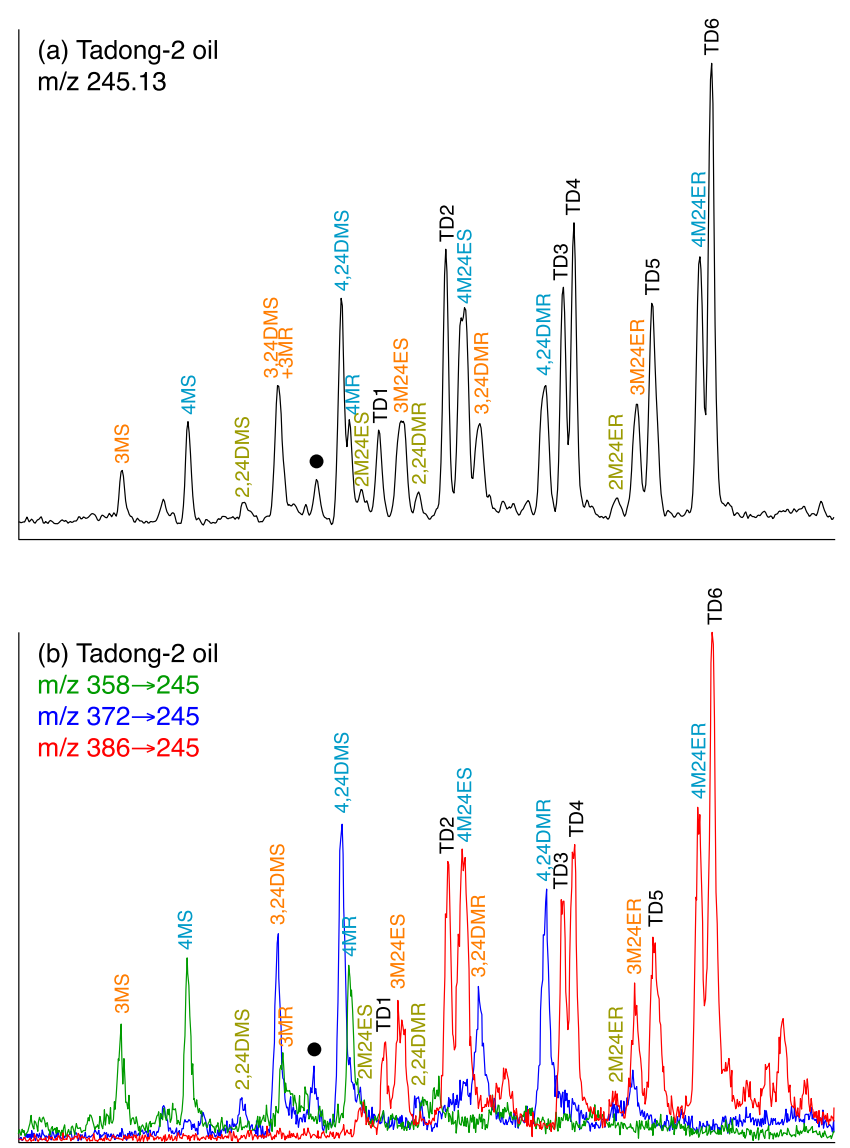

Fig. 3. (a) HR-GC-MS-SIR and (b) quadrupole GC-MS-MS analyses of Tadong-2 oil $(\bullet=$ proposed early eluting, seventh triaromatic dinosteroid peak; see Table 2 for other identifications).

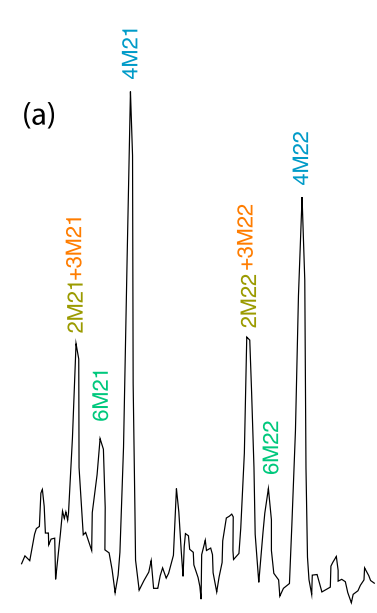

(c)

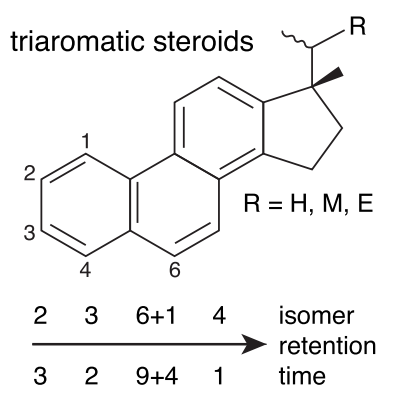

(b) methylphenanthrenes

$\mathrm{m} / \mathrm{z} 274 \rightarrow 245(100 \%)$ $\mathrm{m} / \mathrm{z} 288 \rightarrow 245(50.9 \%)$ $\mathrm{m} / \mathrm{z} 302 \rightarrow 245(14.8 \%)$

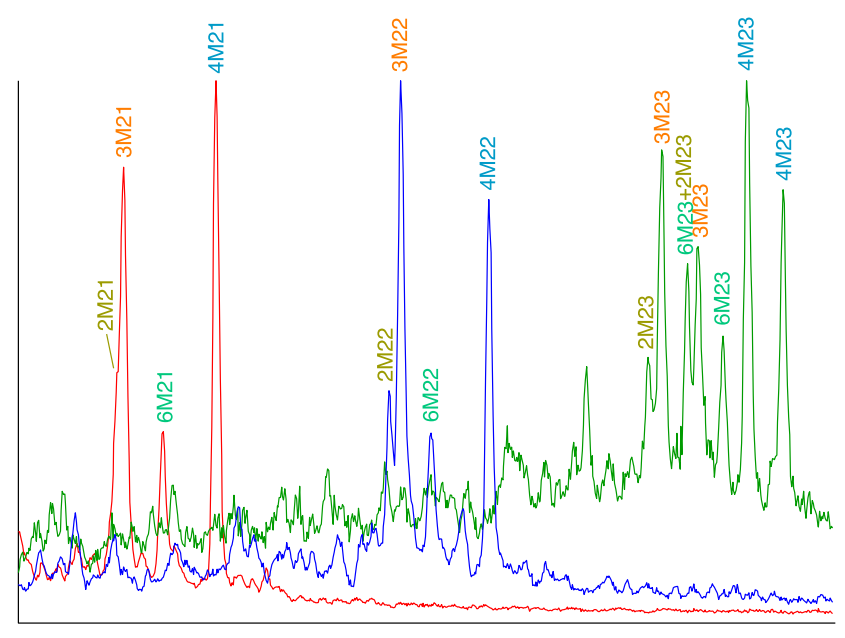

Fig. 4. (a) $m / z 245$ mass chromatogram showing confirmed elution order of isomers in a Triassic oil $(2200 \mathrm{~m})$ from St German Laxis, Paris Basin, by coinjection of $\mathrm{C}_{21}$ synthetic standards on $25 \mathrm{~m} \times 0.3 \mathrm{~mm} \mathrm{SE}-30$ column and temperature programme of $150-300{ }^{\circ} \mathrm{C}$ at $3^{\circ} / \mathrm{min}$. (from Lichtfouse 1989). (b) Theoretical prediction of elution order by comparison with methylphenanthrenes (after Killops, 1986; Lichtfouse, 1989). (c) Proposed isomer distribution in this study, from GC-MS-MS analysis of a gneiss extract (CP-Sil-5 column). See Table 2 for peak identifications.

possible that co-elution of 1- and 6-methyl triaromatic steroids also occurs (Killops, 1986; Lichtfouse, 1989; Lichtfouse et al., 1994).

As might be expected for two series of compounds that differ only in whether a methyl group is present at C-4, the pattern of relative retention times and abundances of each peak within the triaromatic dinosteroid series is almost exactly replicated by the 28-nor series (see Fig. 12c). In both series, the fifth peak is broadened and appears to represent at least two isomers, very closely eluting. Consequently, seven of the possible eight isomers are seemingly accounted for. The eighth may be absent or of extremely low abundance, or it may co-elute with another isomer.

\subsection{Post-Paleozoic variations in isomer distribution}

Potential for variation in triaromatic dinosteroid distributions in $\mathrm{m} / \mathrm{z}$ 245 mass chromatograms was examined in three sets of oils: 
1. Replicate analyses of the NSO-1 standard (oil from the Oseberg Field in the Norwegian North Sea; NIGOGA, 2000) were assessed for variance attributable to experimental conditions (see Appendix 1 for data);

2. Norwegian North Sea oils with at least moderately abundant triaromatic dinosteroids, in order to minimise the influence of quantification errors, but encompassing varying extents maturity and biodegradation and a range of marine vs terrestrial contributions to their Jurassic sources (Appendix 2);

3. Oils from around the world and of varying maturity, biodegradation, source age and depositional environment, but again containing at least moderately abundant triaromatic dinosteroids (Appendix 3).

The abundance of each of the six triaromatic dinosteroid peaks was calculated relative to the total for each sample, and \%RSD was used for comparison of the three sets of oils, as recorded in Table 2.

RSDs for the NSO-1 standard set are $<5 \%$, with TD2 and TD6 showing the least variation, probably because they are the best resolved peaks. The low relative abundance of TD1 may contribute to its slightly poorer reproducibility, and the highest RSD for TD5 is probably at least partially attributable to the likely presence of poorly resolved isomers (Table 2).

The North Sea oil set exhibits slightly greater variance than the NSO1 replicates, although all triaromatic dinosteroid peaks exhibit similar RSDs, all $<8 \%$ (Table 2). Variable contributions from other A/B-ring methylated triaromatic steroids and their lack of baseline resolution from some of the triaromatic dinosteroids probably accounts for the slightly elevated RSDs when compared to the NSO-1 set but, overall, distributions appear similar. Principal component analysis (PCA) was undertaken on the combined data from NSO-1, North Sea oils and some Late Jurassic marine source rock extracts (Draupne and Hekkingen fm shales), with the first two PCs plotted in Fig. 5. The North Sea oils mostly show a similar range of values to the NSO-1 standard, but the most immature samples among the source rock extracts exhibit statistically relevant variability, which is discussed in Section 3.4. A few oils exhibit lower PC1 values than the NSO-1 range, including some of those appearing to represent more mature versions (estimated vitrinite reflectance equivalent $>1 \%$ ) of the C1 family of Justwan et al. (2006), derived from the Late Jurassic Draupne Fm, which here are collectively termed the C3 family. The low PC1 scores of this sub-set of C3 oils seems to be attributable to slight relative depletion of TD6 and TD5.

RSD values for the global oil set are slightly higher again than those of the North Sea oils, although not dramatically so. Other than for TD1 $(\sim 11 \%)$, RSDs are $<9 \%$, again suggesting a fairly consistent pattern of isomer distribution (Table 2). PCA shows a more diffuse distribution in

Table 2

Statistical analysis of variations in relative abundances of the six triaromatic dinosteroid peaks in three sets of oils and some Late Jurassic, immature, marine shale extracts.

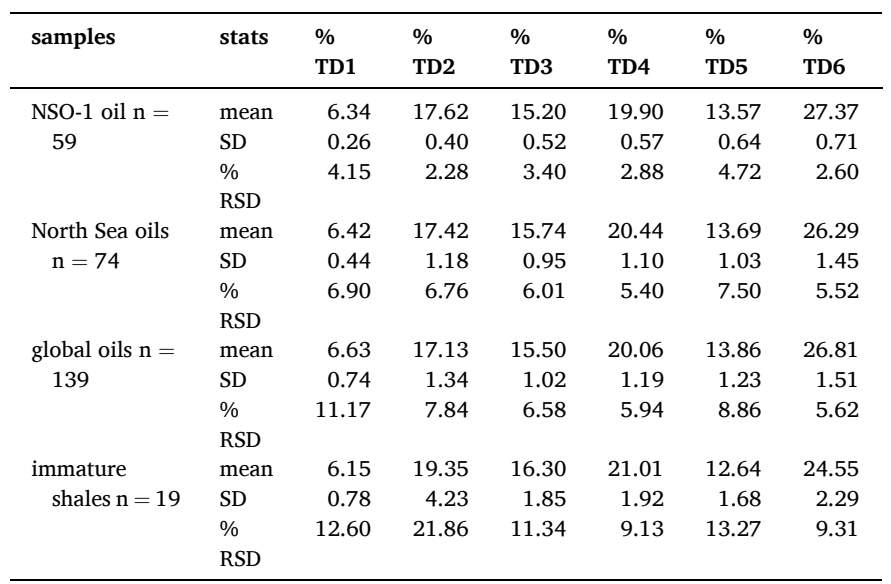

Fig. 6, centred on the NSO-1 replicates. A number of Early Jurassic sourced oils plot at slightly higher PC2 values, but there is no obvious enrichment or depletion of any individual triaromatic dinosteroid isomer. Overall, although there is a little more variation for the global set than the North Sea, there is no clear picture of age-related control on peak distributions in post-Paleozoic oils.

\subsection{Depositional environment}

As noted by Moldowan et al. (1996), triaromatic dinosteroids are most abundant in oils from post-Paleozoic marine sources, reflecting conditions that favour dinoflagellate communities (Taylor, 1987). With increasing higher plant contribution to mixed marine-terrestrial source units, dinosteroid contributions among biomarkers become less distinct. Co-elution problems can obscure recognition of the usual distribution of the triaromatic dinosteroids, or at least adversely affect quantification. Such factors disqualified from this study most oils from the $\mathrm{E}$ and $\mathrm{F}$ families of Norwegian North Sea oils (Justwan et al., 2006), in which the $\mathrm{Pr} / \mathrm{Ph}$ ratio is $\sim 3$, and as a proportion of total $\mathrm{C}_{27}-\mathrm{C}_{30}$ steranes the $\mathrm{C}_{29}$ and $\mathrm{C}_{30}$ (i.e. 24- $n$-propyl) members account for $\sim 35 \%$ and $\sim 5 \%$ respectively. For comparison, the corresponding ratio values for typical Draupne Fm, C family oils are $\sim 1.5, \sim 30 \%$ and $10 \%$.

In the most terrestrially influenced environments, unambiguous identification of triaromatic dinosteroids can become impossible, as observed for the New Zealand oil derived from a coaly Tertiary source in Fig. 7a. This oil is dominated by woody angiosperm contributions and has typically high $\mathrm{C}_{29}$ sterane content ( $\sim 75 \%$ cf total $\mathrm{C}_{27}-\mathrm{C}_{30}$ steranes). Its minimal 24-n-propylcholestane content $(\sim 2 \%)$ reflects the marine incursions that terminate periods of peat accumulation (Killops et al., 1994). Peaks are present in its $m / z 245$ mass chromatogram at the relative elution times of many of the triaromatic dinosteroids, including particularly intense signals at the relative retention times of TD4 and TD6. However, the $m / z 386 \rightarrow 245$ chromatogram provides no clear evidence of triaromatic dinosteroids, apart from possibly TD6. The $m / z$ $414 \rightarrow 231$ transition for the corresponding saturates fraction reveals the presence of 3-methyl- and 4-methyl-24-ethylcholestanes, but no dinosteranes. Of the many small peaks in the relevant retention time interval, none is attributable to a dinosterane isomer upon comparison with an oil containing these compounds and analysed under identical conditions. In such oils, dating via higher plant contributions is to be preferred.

About $10 \%$ of extant dinoflagellate species inhabit freshwater environments, some of the most common genera being Ceratium, Peridinium and Gymnodinium (Pollingher, 1987). Salinity adaptation is key to species distribution and it appears that freshwater colonisation by marine dinoflagellates is, for the most part, an infrequent and ancient event (Logares et al., 2007; Annenkova et al., 2020). It is perhaps not surprising, then, that disparate biomarker distributions are observed for marine and freshwater environments, with the latter being characterised by dominant $4 \alpha$-methyl-24-ethylcholestanes, whereas dinosteranes, if present, are only minor components (Summons et al., 1992; Moldowan et al., 1996). Consequently, a post-Paleozoic lacustrine oil may not contain triaromatic dinosteroids, even if conditions favour dinoflagellate communities. As an example, the oil in Fig. $7 \mathrm{~b}$ represents a Tertiary lacustrine source in SE Asia derived from a dominantly botryococcal kerogen. It contains abundant $\mathrm{C}_{34}$ botryococcane and tetracyclic polyprenoids, has a high $\mathrm{C}_{26} / \mathrm{C}_{25}$ cheilanthane ratio (1.6), and no detectable marine 24-n-propylcholestanes or 27-norcholestanes. These characteristics are consistent with a fresh/brackish lacustrine environment (Volkman, 1988; Holba et al., 2003). 4-Methylsteroids dominate both the $m / z 245$ chromatogram from the aromatics fraction and $m / z 414 \rightarrow$ 231 chromatogram from the saturates (Fig. 7b). Triaromatic dinosteroids are present, but at relatively low levels, and it is uncertain whether there are traces of dinosteranes. 


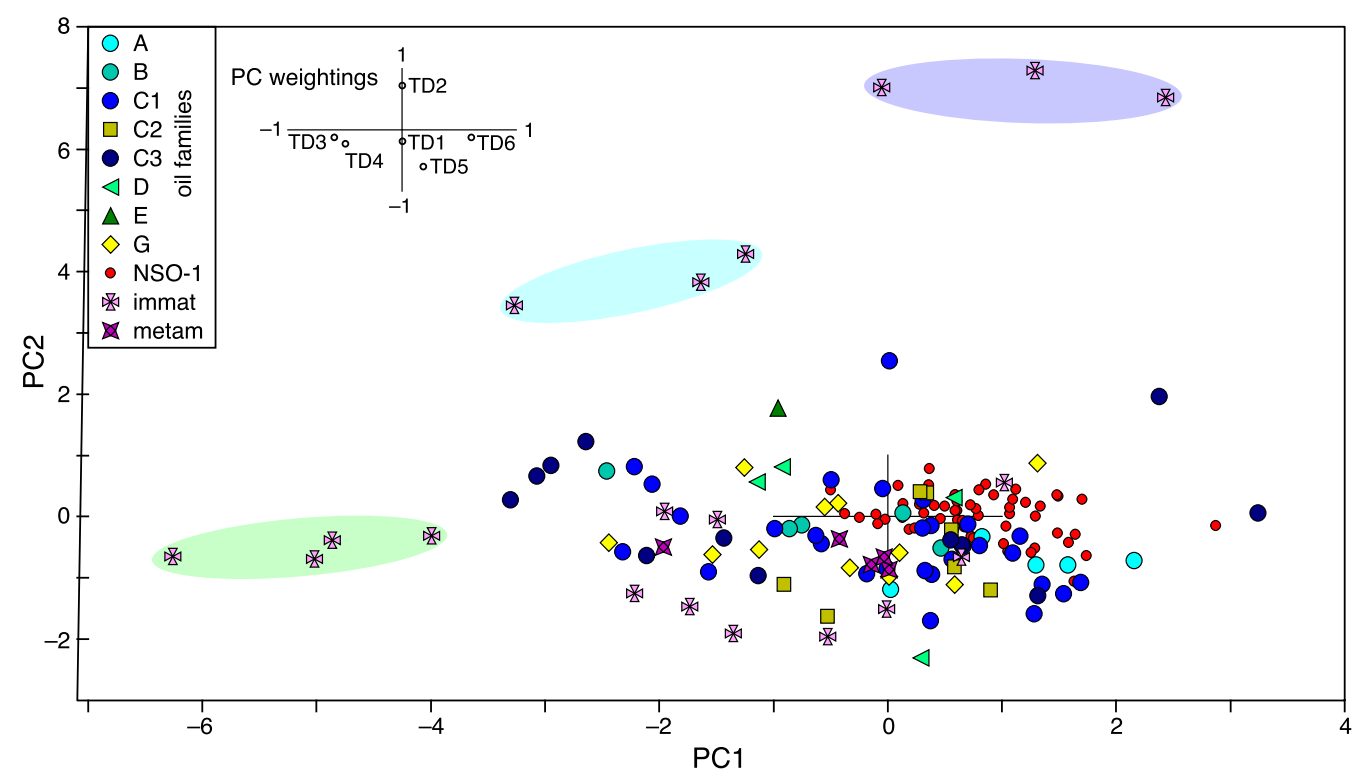

Fig. 5. First two principle component scores for Jurassic sourced Norwegian North Sea oils, associated replicate analyses of NSO-1 standard, Late Jurassic Draupne and Hekkingen fm marine source rock extracts, and some samples of extracted oil that has experienced drill-bit metamorphism. North Sea oils are identified by family (after Justwan et al., 2006): A-C1 are thought to derive from Draupne Fm (anoxicity increasing from $\mathrm{C} 1$ to $\mathrm{A}$ ), with $\mathrm{C} 3$ a high maturity equivalent; $\mathrm{G}$ appears to represent more humic Heather Fm (Late Jurassic); C2 is probably of mixed Draupne-Heather fm origin; E is correlated with coaly Sleipner Fm (Mid Jurassic); D could be a mixture from all three Jurassic units. Coloured areas represent outlier immature shale extract clusters (see Fig. 9a).

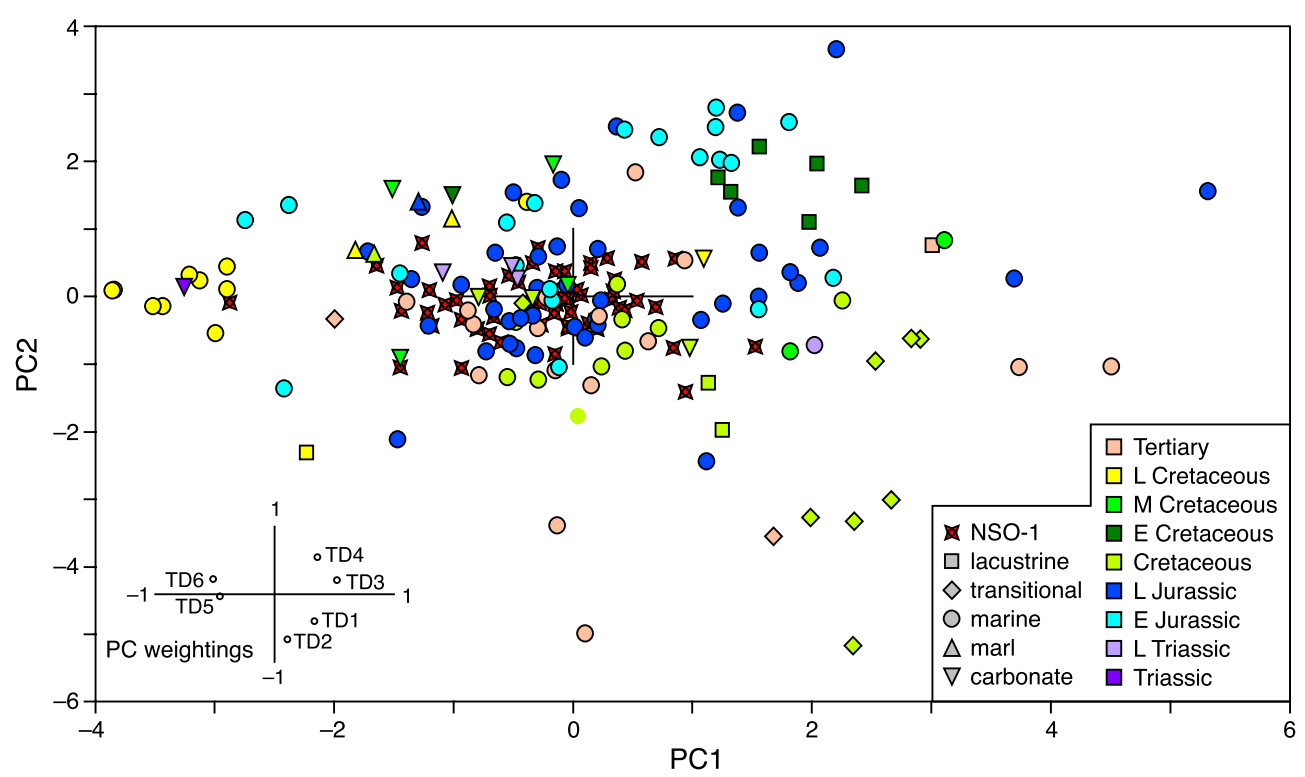

Fig. 6. First two principle component scores for oils derived from a range of source rock ages and depositional environments (see Appendix 3), showing Norwegian NSO-1 standard for reference.

\subsection{Maturity and metamorphism}

Triaromatic dinosteroid distributions towards the low end of the maturity range were examined in samples of Late Jurassic marine shale from the Draupne Fm in the Norwegian North Sea and the Hekkingen Fm, its equivalent in the Norwegian Barents Sea (e.g. Matapour and Karlsen, 2018). The kerogen in these units comprises mostly type II, with varying, minor contributions from type III (Keym et al., 2006). The study samples range from immature to early oil window and are of fairly uniform organofacies, based on biomarker distributions (equivalent to the Draupne Fm C1 oil family of Justwan et al., 2006). Although triaromatic dinosteroid distributions appear to be largely unaffected by maturity variation within the oil window, at lower maturities of $<0.5 \%$ vitrinite reflectance, when diasterenes are still abundant, the relative proportion of TD2 among the isomers appears to be enhanced and that of TD5 is depressed slightly (Fig. 8). The distribution of triaromatic 28-nordinosteroids seems to behave similarly, although it is more difficult to evaluate because other triaromatic steroids are usually more abundant and interfere with quantification of several of the 28-nordinosteroid peaks.

The variations in relative abundance of TD2 and TD5 appear to be restricted to $20 S /(20 S+20 R)$ ratios for $5 \alpha, 14 \alpha, 17 \alpha$-24-ethylcholestane of $<20 \%$ (Fig. 9a). These combined low-maturity abundance variations, shown by the coloured groupings in Fig. 9a, give rise to the correspondingly coloured outlier clusters in Fig. 5. The ratio of TD2/TD6 yields a more gradual transition with maturity, as represented by either the $20 S /(20 S+20 R)$ sterane ratio or the ratio of $10 \alpha$-24-ethyldiacholest13,17 -ene $(20 S+20 R)$ to $5 \alpha, 14 \alpha, 17 \alpha$-24-ethylcholestane $(20 S+20 R)$ in Fig. 9b. It seems likely that the observed trends result from a change in dominance of biologically conferred configuration(s) to one representing a thermodynamic equilibrium mixture by a maturity corresponding to $\sim 30 \%$ for the sterane $20 \mathrm{~S} /(20 \mathrm{~S}+20 \mathrm{R})$ ratio. The causes may include isomerism during early diagenesis as well as compositional differences between bitumen inherited from diagenesis and that subsequently 
(a)

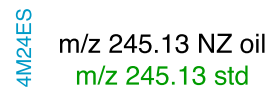

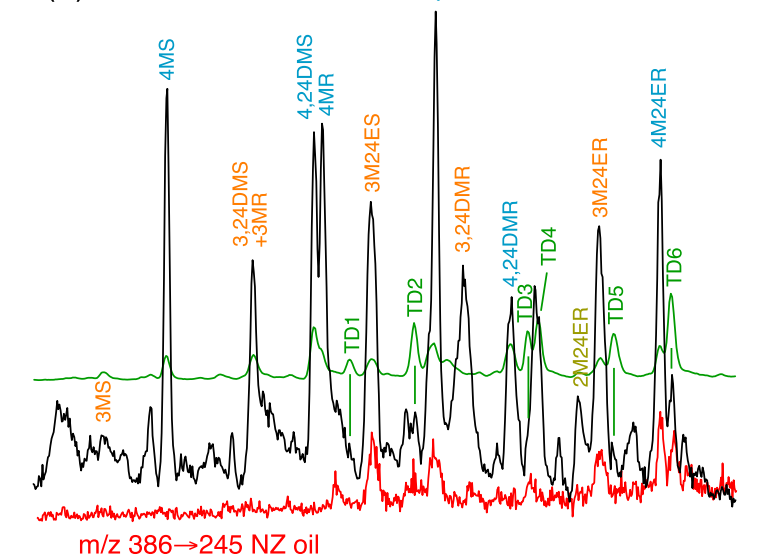

$\mathrm{m} / \mathrm{z} 386 \rightarrow 245 \mathrm{NZ}$ oil

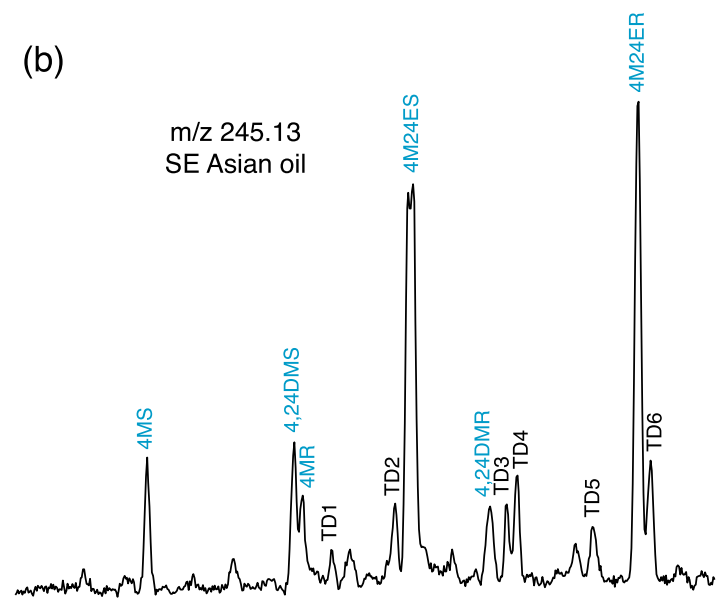

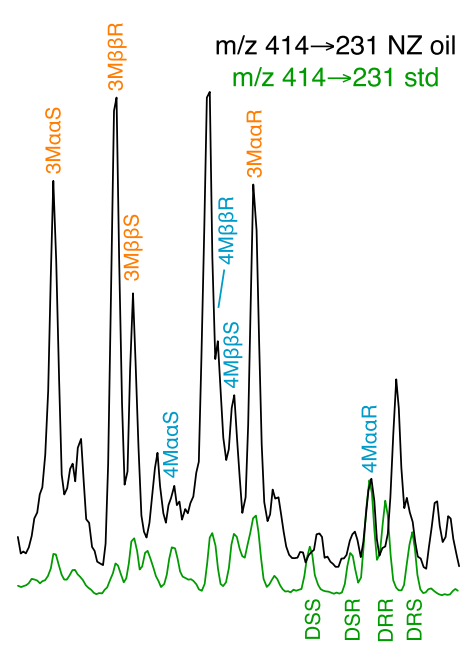

Fig. 7. Problematical identification of dinosteroids in oils from sources with minimal marine contributions using HR-GC-MS of total hydrocarbons and GC-MS-MS of saturates. (a) Dominantly Tertiary coal sourced oil from Taranaki Basin, New Zealand, showing expected elution positions of dinosteroids by comparison with another oil known to contain them (green). (b) Tertiary fresh/brackish lacustrine sourced oil from SE Asia. (For interpretation of the references to colour in this figure legend, the reader is referred to the web version of this article.)
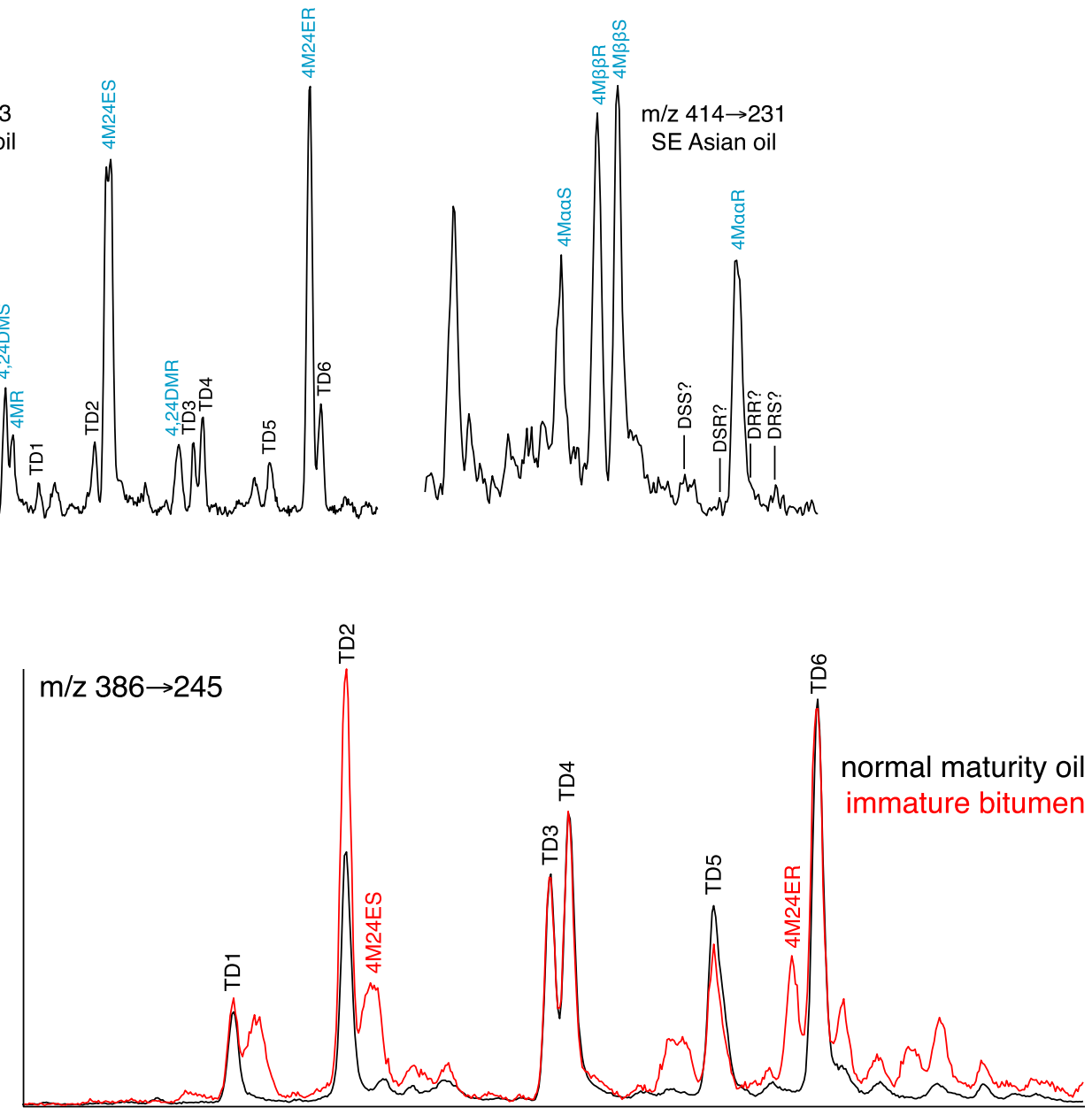

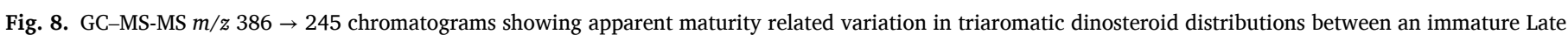
Jurassic marine shale from Norway and a genetically related oil (see Table 2 for peak identifications).

generated from kerogen. Because the underlying data are from a limited number of samples from a uniform organofacies, the wider applicability of the maturity trends in Fig. 9 is uncertain, but source-age inferences from oils will not be impacted.

Triaromatic dinosteroid generation appears to tail off towards the end of the oil window in the same way as for other biomarkers (the potential effect of thermal destruction is discussed below). This is demonstrated by a suite of oils from the southern Norwegian North Sea in Fig. 10, which represent trapping of oil over different source maturity ranges (estimated from a combination of biomarker, aromatic and light hydrocarbon parameters). The abundances of all triaromatic steroids decline with increasing maturity, as demonstrated by the $m / z 245$ mass chromatogram, and by the late oil window only depleted diasteranes, diahopanes, neohopanes and cheilanthanes remain among routinely monitored biomarkers.

For triaromatic steroids in general, no evidence has been obtained for the direct formation of short-chain components by cracking of the alkyl chain at C-24 (Beach et al., 1989). A similar observation can be made for 


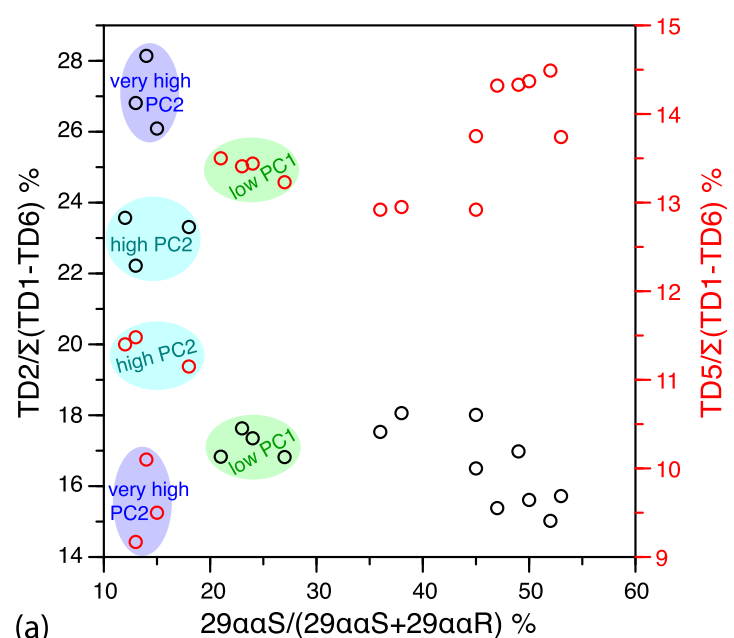

(a)

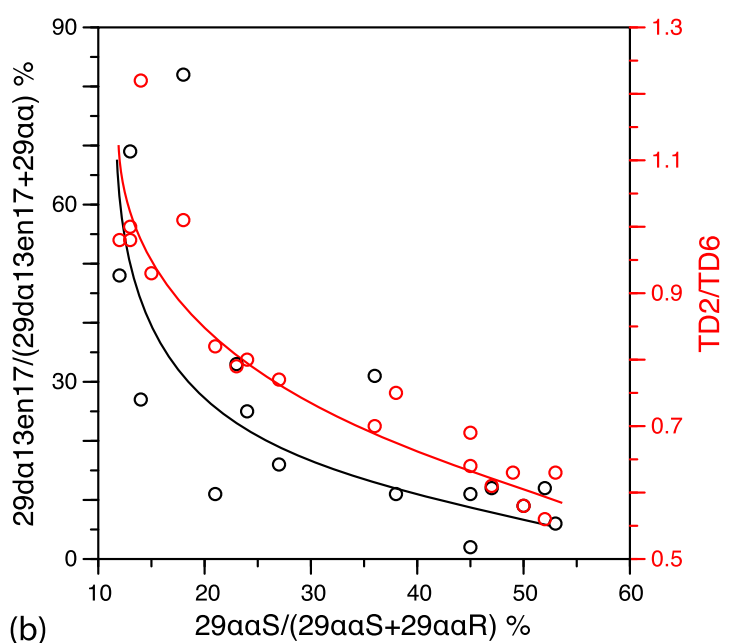

(b)

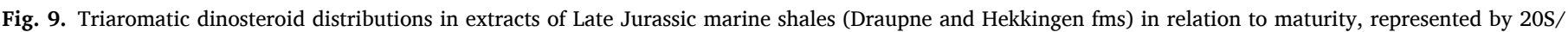

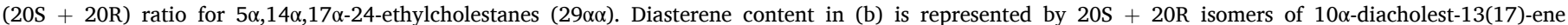
(29d $\alpha 13$ en17). Coloured PC clusters in (a) refer to PCA analysis in Fig. 5.

the triaromatic dinosteroids. Based on the thermodynamic stabilities of methylphenanthrenes $(2 \mathrm{M} \approx 3 \mathrm{M}>1 \mathrm{M} \approx 9 \mathrm{M}>4 \mathrm{M}$; Szczerba and Rospondek, 2010), those of the A-ring methylated triaromatic steroids are predicted to be $2 M \approx 3 M>6 M \approx 4 M>1 M$ (see Fig. $4 \mathrm{~b}$ for structural comparison). Consistent with this prediction, and as previously observed by Lichtfouse et al. (1990, 1993, 1994), the 4- and 6-methyl series appear less thermodynamically stable than the 3-methyl in Fig. 10. This apparent generation/stability effect may obscure any production of the 4-methylsteroids by cracking of the C-24 side-chain of $\mathrm{C}_{28}-\mathrm{C}_{30}$ members of either the triaromatic 4-methylsteroids or the triaromatic dinosteroids. There is also potential for diagenetic rearrangement involving methyl group shifts, favouring C-3 over C-4 substitution on the final triaromatic hydrocarbons, similar to the isomerism proposed for methylphenanthrenes (Lichtfouse, 1989; Szczerba and Rospondek, 2010). Assuming the maturity inferences from Fig. 10 are typical, age indications from triaromatic dinosteroids are likely to become less reliable towards the end of the oil window as concentrations decrease, and the relative abundance of potentially related short-chain 4-methyl steroids are not of assistance.

The influence of thermal stability variation on biomarker distributions can be difficult to disentangle from that of declining generation from kerogen, but is of significance to oil accumulations affected by igneous intrusions. Some insight may be obtained from the effects of drill-bit metamorphism. In Fig. 11 biomarker distributions in oil stained core from crystalline basement in the Norwegian North Sea that has been affected by drill-bit metamorphism are compared to those of the equivalent, relatively unaltered, test oil. This example suggests that triaromatic dinosteroids and their 28-nor counterparts are among the most thermodynamically stable of biomarkers. There is no obvious alteration of triaromatic dinosteroid isomer distributions, although the rapid extreme heating may obscure subtle differences in thermodynamic stability. It is possible, therefore, that any triaromatic dinosteroids present in oil from a pre-Mesozoic source could be enriched relative to other biomarkers by a degree of metamorphism, potentially affecting age assessment.

\subsection{Biodegradation}

It has been proposed that triaromatic dinosteroids are among the most resistant of biomarkers towards biodegradation (Killops et al., 2019), an observation supported by recent work on northern Alberta oil sands (Bennett and Jiang, 2021). Severe biodegradation can result in the compounds becoming enriched to the extent that they dominate $m / z 245$ responses, and the 28-nor counterparts will also significantly increase in relative abundance (Fig. 12). The triaromatic dinosteroids appear to persist, with no obvious change in isomeric distribution, when other A/ B-ring methylated triaromatic steroids have been almost eliminated. It is possible that the presence of an additional tertiary centre at C-23 confers particular resistance towards biodegradation, at least for the anaerobic consortia involved in the example in Fig. 12.

In terms of sensitivity towards biodegradation among other $\mathrm{C}_{27}-\mathrm{C}_{29}$ methylated triaromatic steroids, it is difficult to ascertain whether there are significant differences between the 3-and 4-methyl series because of their low levels in the degraded stain (Fig. 12). In contrast, the $\mathrm{C}_{21}$ and $\mathrm{C}_{22}$ members of the 3-and 6-methyl members seem to be degraded at a similar rate that is slower than for the 4-methyl components. It is not possible to conclude whether there is any biodegradative conversion of $\mathrm{C}_{27}-\mathrm{C}_{29}$ triaromatic A-ring methylated steroids to $\mathrm{C}_{21}$ and $\mathrm{C}_{22}$ homologues. Overall, severe biodegradation results in enrichment of triaromatic dinosteroids similar to that observed for extensive thermal alteration.

\subsection{Paleozoic occurrences}

There are few examples of triaromatic dinosteroids in Paleozoic oils. It has been suggested that the Tadong- 2 oil from the Tarim Basin analysed in this study has mixed origins (Bao et al., 2018), so it may not be the most reliable example. Its abundant triaromatic dinosteroids and other biomarker characteristics are certainly unusual for a Cambrian source and more like those of a Mesozoic. For example, 24-norcholestanes are abundant (Holba et al., 1998), phyllocladane is present (Disnar and Harouna, 1994) and there appear to be traces of oleanane and its des-A counterpart (Moldowan et al., 1994). The presence of 24-n-propylcholestanes but elevated TPP ratio would normally suggest a mixed contribution from fresh/brackish lacustrine and marine units (Holba et al., 2003). Hopane isomerism is incomplete and steranes are dominated by $20 R$ isomers, suggesting a maturity of $<0.6 \%$ vitrinite reflectance, whereas light hydrocarbon Thompson $\mathrm{H}$ and $\mathrm{I}$ values infer a higher maturity of $1.1-1.2 \%$ vitrinite reflectance (Thompson, 1983). Together, these maturity characteristics could imply mixed contributions of disparate maturities. The biomarker distributions are difficult to reconcile with a Cambrian dolomitic source of vitrinite reflectance $\sim 2 \%$ (Wang et al., 2006), even allowing for some metamorphic enrichment of triaromatic dinosteroids. For the Tadong- 2 oil, the relative proportions of TD1-TD6 are 5.92, 17.31, 14.79, 18.96, 13.80 and 29.21\%, respectively, which are within $2 \sigma$ of all means for the global oil set in Table 2 , 

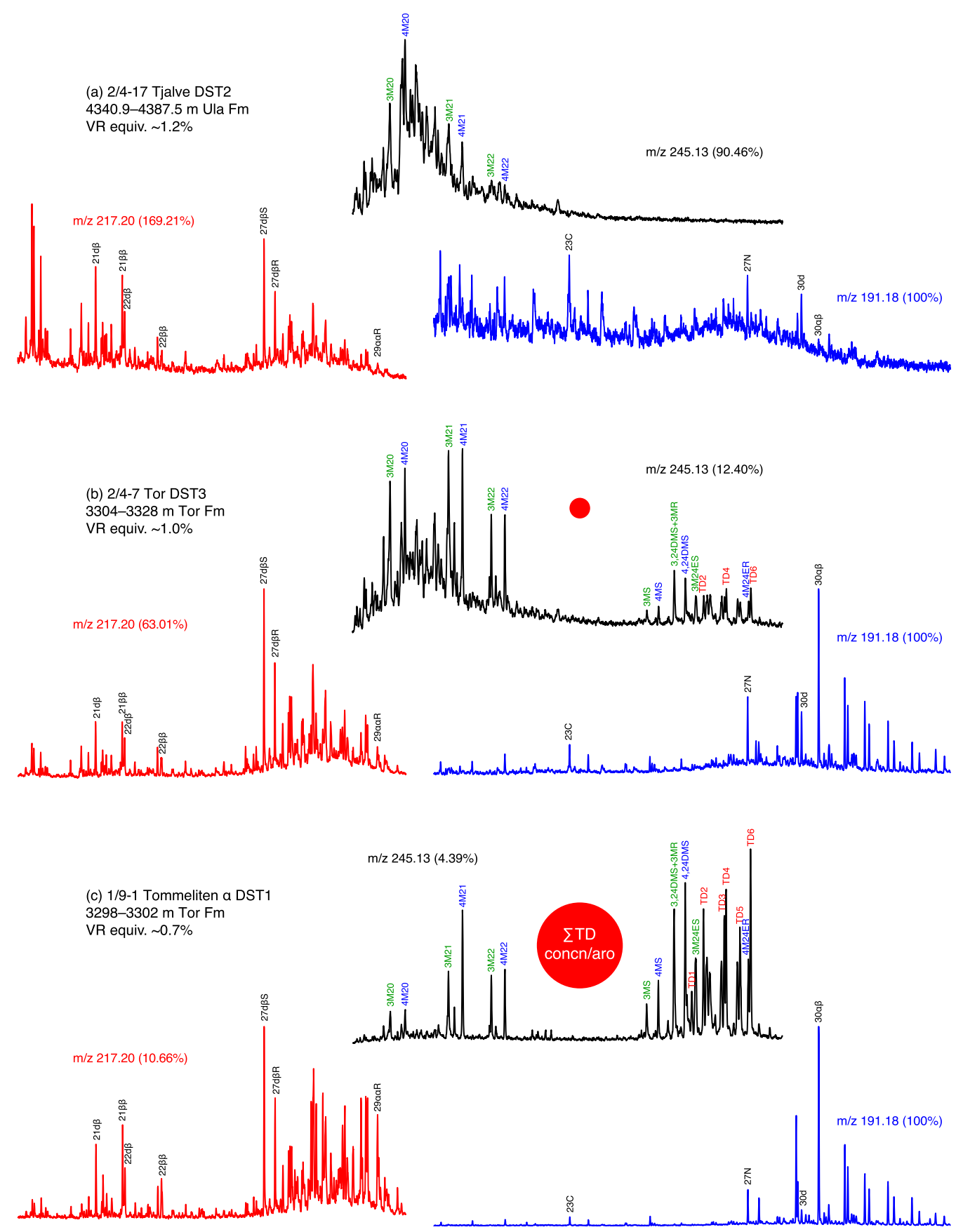

Fig. 10. HR-GC-MS-SIR mass chromatograms showing variation in triaromatic dinosteroid abundance relative to other biomarkers as a function of inferred mean maturity (increasing from c to a) for some Norwegian North Sea oils. Red circles represent relative proportion of aromatic fraction contributed by $\Sigma$ (TD1-TD6) [effectively zero in (a)]. Response factors relative to $100 \%$ for $m$ / z 191 are also shown. See Table 2 for peak identifications. (For interpretation of the references to colour in this figure legend, the reader is referred to the web version of this article.) and mostly within $1 \sigma$, so the distribution is not unique, although the overall biomarker characteristics may represent a unique Cambrian ecosystem.

The possibility that isomeric distributions vary in pre-Mesozoic samples cannot be entirely discounted, although it is unlikely that they would differ from post-Paleozoic examples on the basis of the apparent development of a thermodynamic equilibrium mixture by the onset of the oil window. An example of a Vendian-Cambrian sourced oil from Siberia - containing typically elevated 24-isopropylcholestanes and 3-methylsteranes, and with steranes dominated by $\mathrm{C}_{29}$ components -is shown in Fig. 13, along with equivalent chromatograms from the NSO-1 oil (underlain in red to indicate the elution positions of dinosteroids). Peaks T, V and W elute closely to, but not precisely with, triaromatic dinosteroids in the $m / z 245$ mass chromatogram in Fig. 13a, but there is a signal coinciding with the relative retention time of TD6.
The $m / z 386 \rightarrow 245$ chromatogram (Fig. 13c) shows that A-ring methylated 24-ethylcholesteroids are present and that the unidentified peaks $\mathrm{T}-\mathrm{Z}$ also seem to contain $\mathrm{C}_{29}$ tetracyclic triaromatics capable of generating a $m / z 245$ fragment ion. The peak at the retention time of TD6 is greatly enhanced relative to the 3- and 4-methyl-24-ethylcholesteroids in the $m / z 386 \rightarrow 245$ chromatogram compared to the $m / z 245$ SIR chromatogram, which is not typically observed (cf. Fig. 3), so it is debatable whether TD6 is present as possibly the only triaromatic dinosteroid. There are no signs of dinosteranes in the $m / z 414 \rightarrow 231$ chromatogram in Fig. 13b. Consequently, reliance on one or two peaks in $m / z 245$, or even $m / z 386 \rightarrow 245$, chromatograms to infer the presence of triaromatic dinosteroids is best avoided. 


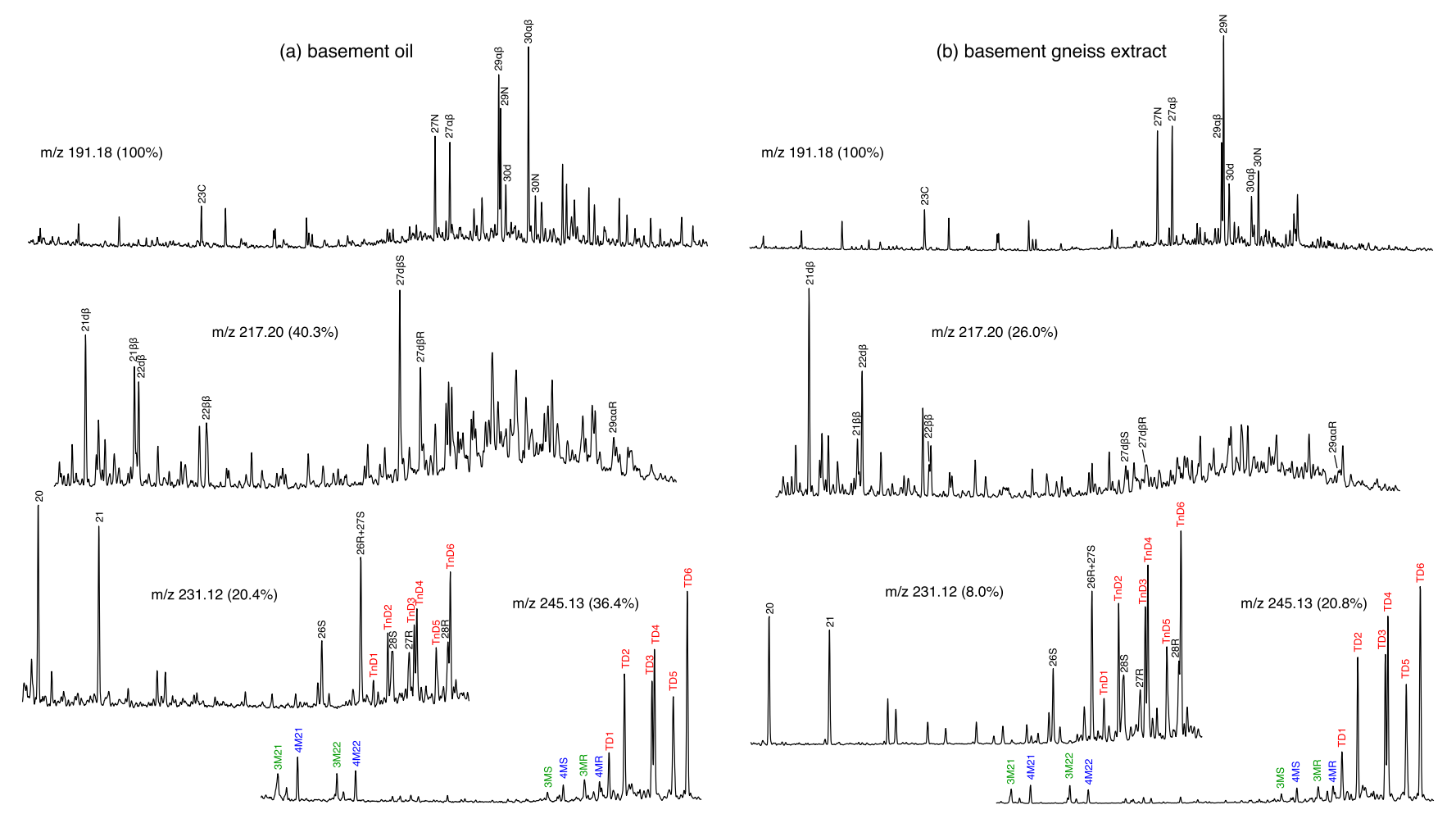

Fig. 11. HR-GC-MS-SIR mass chromatograms showing influence of drill-bit metamorphism on a Norwegian North Sea oil. (a) Largely unaltered basement test oil; (b) basement gneiss extract exhibiting metamorphism. See Table 2 for peak identities. Response factors are relative to $100 \%$ for $m / z 191$.

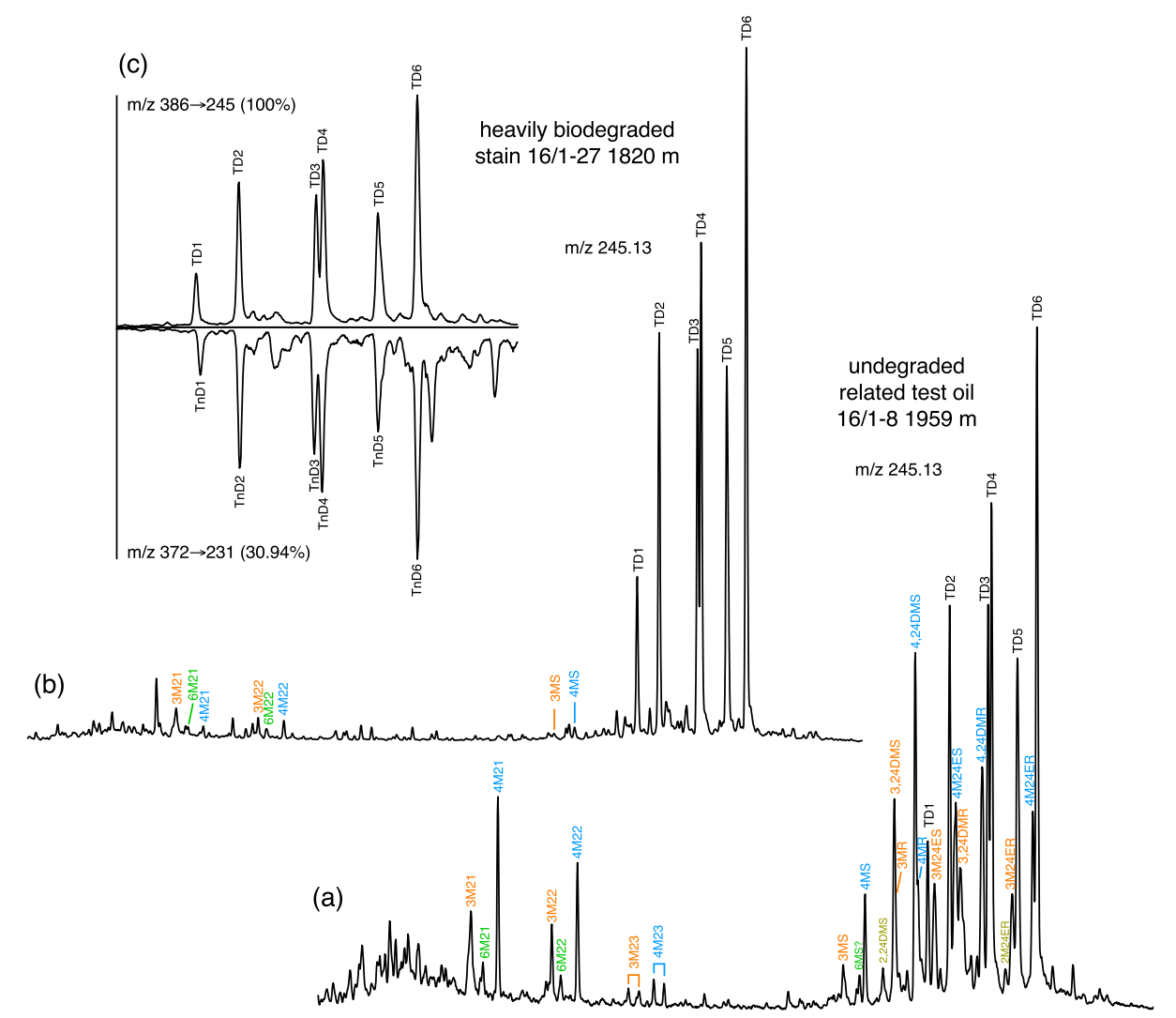

Fig. 12. Enrichment of triaromatic dinosteroids relative to other A/B-ring methylated triaromatic steroids as a result of severe biodegradation observed in $\mathrm{m} / \mathrm{z} 245.13$ mass chromatograms of genetically related unaltered oil (a) and degraded stain (b) from North Sea exploration wells (after Killops et al. 2019). GC-MS-MS transitions for the biodegraded oil (c) show the similarity in distribution of triaromatic dinosteroids (TD in $\mathrm{m} / \mathrm{z} 386 \rightarrow$ 245) and their 28-nor counterparts (TnD in $m / z 372$ $\rightarrow 231$ ), after off-setting time axes to emphasise correspondence of isomer patterns. See Table 2 for peak identifications.

\subsection{Combined dinosteroid parameter plots}

Age parameters derived from the Norwegian North Sea and global oil data sets (see Appendices 2 and 3, respectively) are plotted in Fig. 14. The North Sea data define a well constrained trend, with the more humic influenced oils (E and G families; Justwan et al., 2006) tending to plot in 


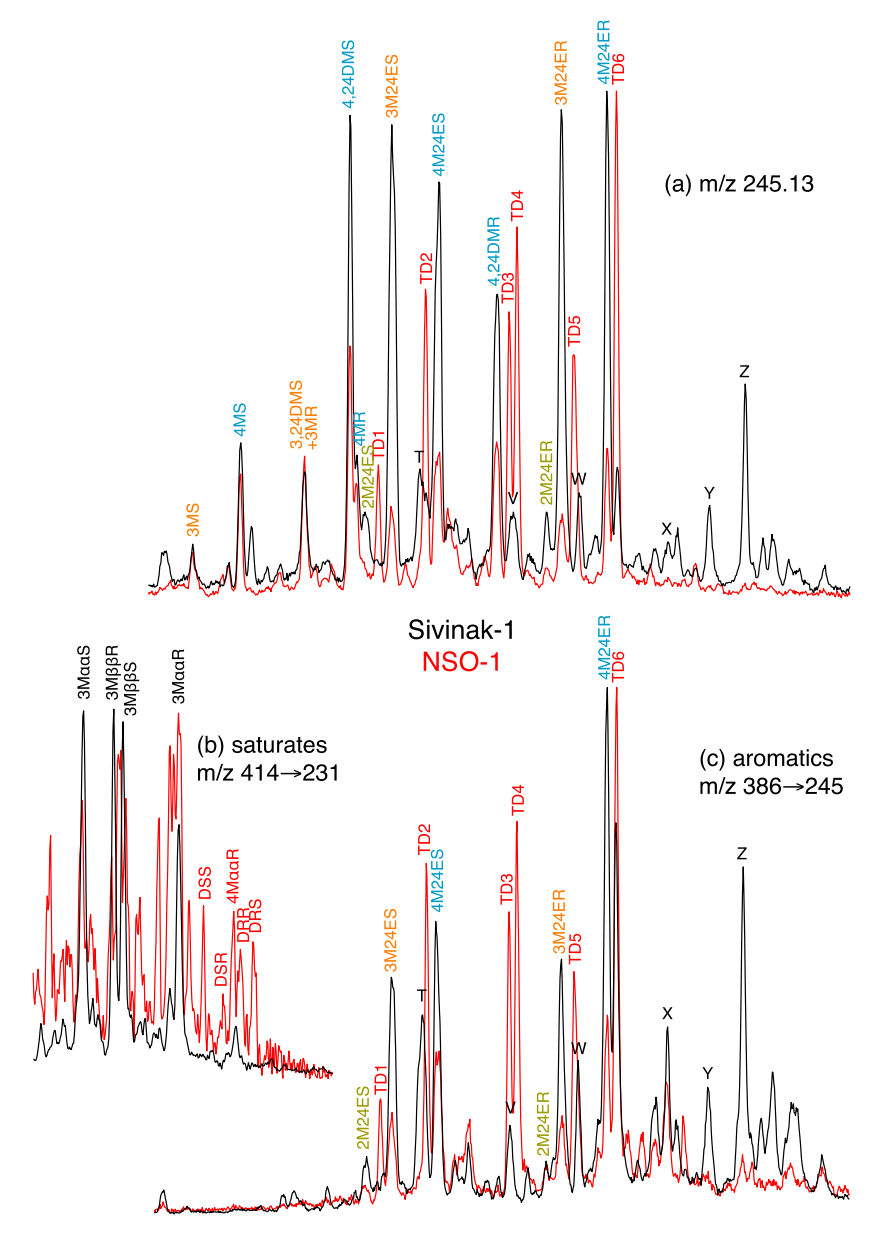

Fig. 13. A-ring methylated steroid distributions in a Russian oil from a likely Vendian-Cambrian source: (a) HR-GC-MS-SIR of total hydrocarbons; (b) GC-MS-MS of saturates; (c) GC-MS-MS of aromatics. Chromatograms in red represent the NSO-1 standard oil to aid component identifications. Peaks T-Z are unidentified; see Table 2 for key to other compound identities. (For interpretation of the references to colour in this figure legend, the reader is referred to the web version of this article.)

the lower range of the triaromatic dinosteroid parameter, along with high maturity charges from the marine Draupne Fm (C3 family). Oils from the most anoxic facies of the Draupne Fm (A family) tend to exhibit higher values, although the more common Draupne Fm C1 family spans the entire range. Late Jurassic marine sourced oils from the global data set (grey circles, Fig. 14a) fit the general North Sea trend. For replicate analyses of the NSO-1 standard, the $95 \%$ confidence range for the triaromatic dinosteroid parameter is only $\pm 0.74 \%$, whereas for the 28 -nordinosteroid parameter it is $\pm 5.14 \%$. The latter, lower precision is probably attributable to the relatively low abundance of the 28-nordinosteroid peaks compared to other triaromatic steroids in $\mathrm{m} / \mathrm{z} 231$ mass chromatograms, the use of a single isomer/peak in the ratio, and the possibility of co-eluant interference.

The global oil data span a slightly greater range of parameter values in Fig. 14b. Cretaceous marine oils tend to plot at higher values of the 28-nordinosteroid parameter than the North Sea trend, which may result from an additional contribution of the 28-nordinosteroids (e.g. diatoms). Early Jurassic marine oils from Western Europe form two clusters, one of which has low parameter values that fall on the extended North Sea trend. The cluster at higher values plots mostly with the Cretaceous samples, but its Jurassic age suggests that any supplementary contribution of 28-nordinosteroids is unlikely to derive from diatoms (Rampen et al., 2009; Cermeño, 2016). It is important to remember that the dataset is limited in size and to samples with relatively abundant and well resolved triaromatic dinosteroids. Even so, the fact that a few Triassic-sourced oils exhibit moderate values for the dinosteroid age parameters suggests that it is not always possible to distinguish Triassic from younger sources (as concluded from the dataset available to Barbanti et al., 2011). It does not appear that age resolution at the Period level can be achieved with confidence for post-Paleozoic oils, even in the absence of severe biodegradation and thermal alteration, which shift both parameter values towards $100 \%$.

There is no clear resolution of samples on the basis of depositional environment in Fig. 14b. Post-Paleozoic lacustrine sourced oils cannot be relied upon to contain triaromatic dinosteroids. Although the 28-nordinosteroid age parameter can be more helpful in dating such oils, zero values are still possible. This parameter exhibits the greatest variation in the global data set (0-37\%; Fig. 14b), presumably reflecting a greater variety of phytoplankton assemblages than the more cosmopolitan marine communities. Diatoms are potentially significant contributors of 28-nordinosteroids in lacustrine settings from the end of the Cretaceous (Siver et al., 2016).

\section{Conclusions}

Evidence could not be found to substantiate a previously cited early eluting, seventh, resolved isomer of the triaromatic dinosteroids, or of a 28-nor counterpart. No GC-MS-MS signal was observed corresponding to a $\mathrm{C}_{29}$ A-ring methylated triaromatic steroid in the appropriate retention time range for the Tadong-2 oil, but the $m / z 245$ SIR signal could be due to a $\mathrm{C}_{28}$ component. Only the six triaromatic dinosteroid peaks commonly reported were observed, although a broadened fifth peak suggests it comprises at least two isomers. Isomer distributions in study oils from post-Paleozoic sources - mostly marine shales but also some representing carbonate, lacustrine and transitional settings - were found to vary only slightly more than those from replicate analyses of an oil standard (NSO-1), probably mostly as a result of co-elution with other A-ring methylated triaromatic steroids. Samples with particularly low levels of the compounds were excluded from statistical analysis in order to limit the influence of co-eluants on quantification.

As might be expected for two compound series differing only by the presence or absence of a methyl group at C-4, the pattern of relative retention time and abundance observed within the triaromatic dinosteroid series is effectively duplicated by the 28-nordinosteroid series. Triaromatic dinosteroid peak distribution varies little within the oil window, but below $\sim 0.5 \%$ VR in Late Jurassic marine shales from the Norwegian Draupne and Hekkingen fms, when diasterenes are still abundant, extracted bitumen is characterised by enhanced abundance of the second eluting peak but slight depression of the fifth. Whether this observation can be applied universally requires further investigation, but it is unlikely to be of practical importance when analysing oils. The behaviour may reflect thermodynamic equilibration between isomers by $0.5 \%$ VR.

No verifiably Paleozoic or older oil containing identifiable triaromatic dinosteroids was available for comparison of isomer distributions. However, pre-Mesozoic marine oils, and oils from dominantly terrestrial sources, can exhibit minor peaks at similar relative retention times to some of the triaromatic dinosteroids in $\mathrm{m} / \mathrm{z} 245$ and $\mathrm{m} / \mathrm{z} 386 \rightarrow$ 245 chromatograms, particularly the latest-eluting peak (TD6). These peaks seem likely to represent co-eluants rather than dinosteroids, so caution is required when attributing source-age where it is not possible to identify a complete series with appropriate relative abundances.

The generation rate of triaromatic dinosteroids from kerogen appears to decline in a similar way to that of other biomarkers towards the end of the oil window, based on analysis of Norwegian North Sea oils representing varying mean source maturities. However, both triaromatic dinosteroids and their 28-nor analogues are suggested to be thermodynamically more stable than most biomarkers, even slightly more so than diahopane. Evidence for this behaviour was obtained from a comparison of oil extracted from fractured basement core that had 


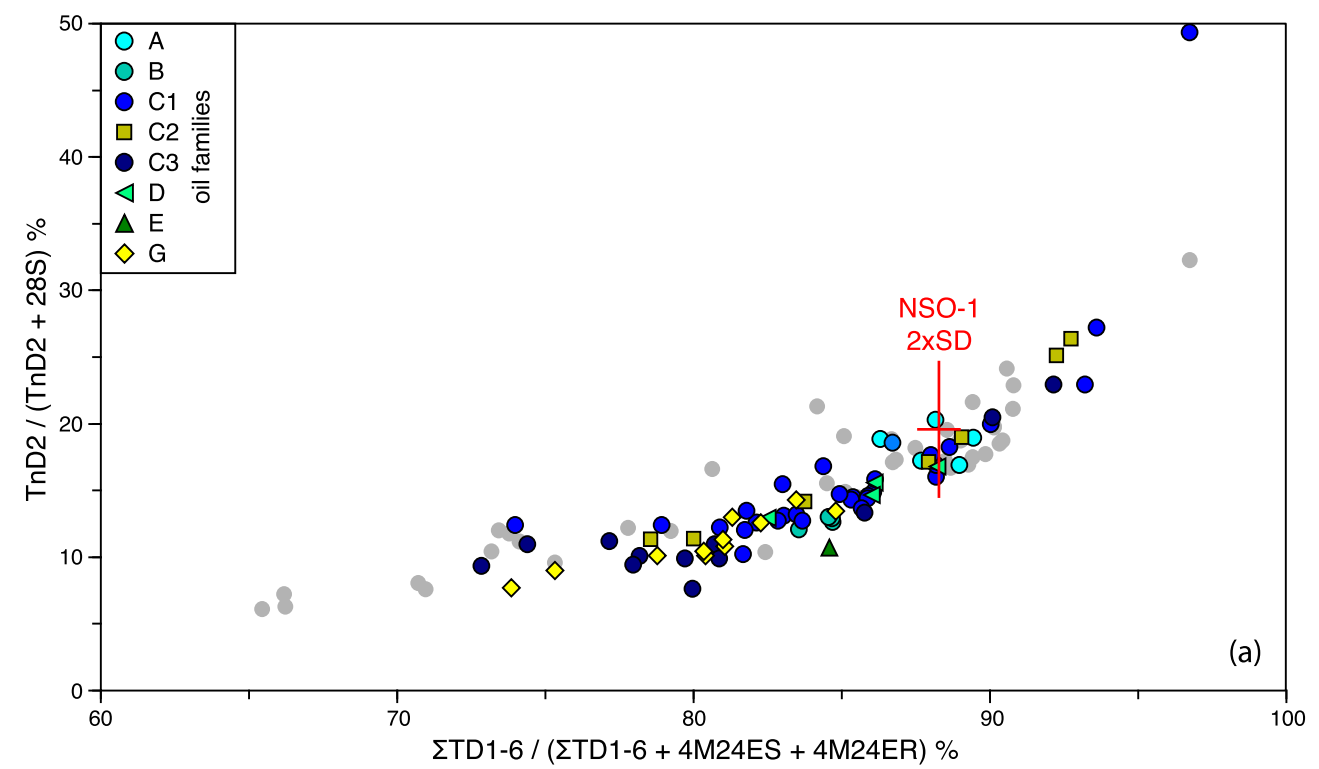

Fig. 14. Plots of age parameters based on triromatic dinosteroids and their 28-nor counterparts (see Table 1 for compound abbreviations). (a) Data for Norwegian North Sea oils from Jurassic sources (see Appendix 2 for details; oil families after Justwan et al., 2006; C3 = mature equivalents of C1; grey circles show Late Jurassic oils from global data set. $95 \%$ confidence limits shown for replicate NSO-1 analyses. (b) Data for global oil data set (see Appendix 3 for details; grey circles show Norwegian North Sea oils). One Tertiary lacustrine sample plots off-scale (35.9 on abscissa, 0.0 on ordinate)

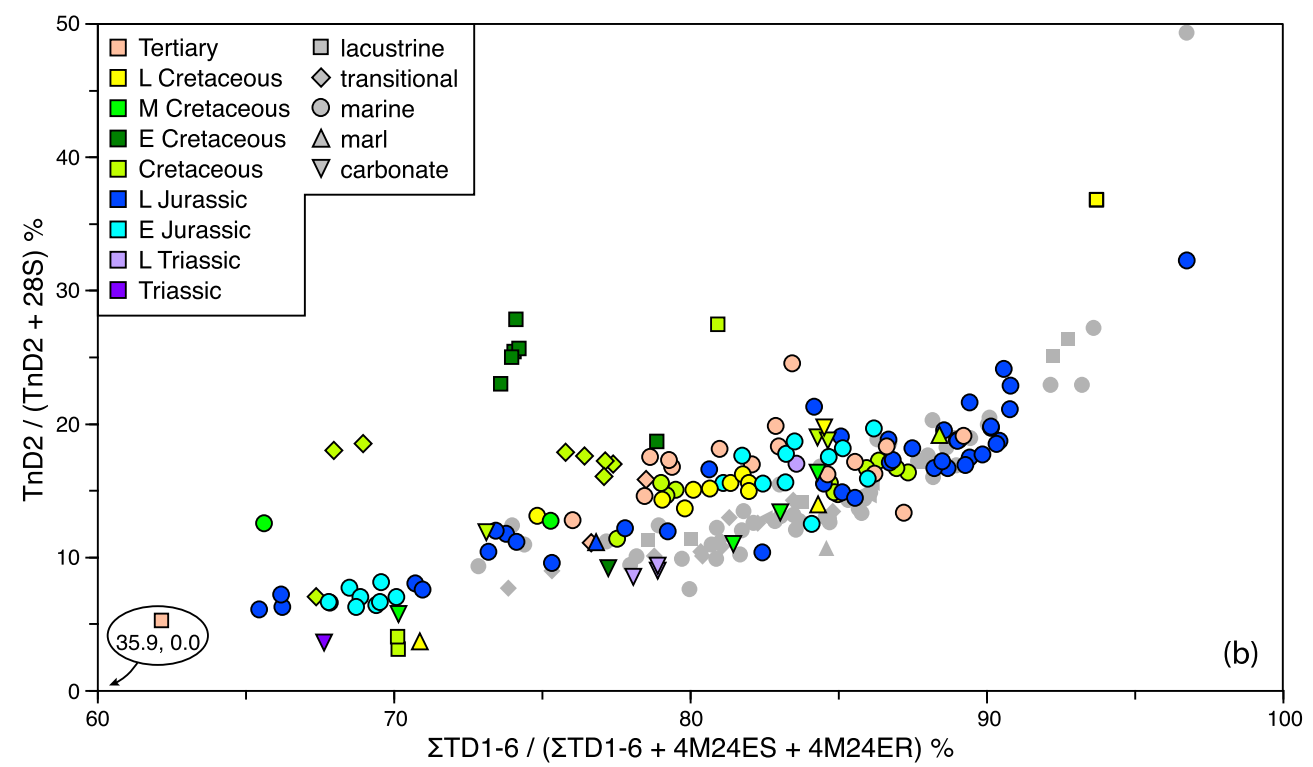

experienced drill-bit metamorphism with the corresponding, largely unaltered, test oil. Further examples are required to confirm this observation.

Both dinosteroid series appear particularly resistant towards biodegradation - at least under the anaerobic conditions investigated and show no obvious change in isomeric distributions. Under severe conditions they become enriched among residual biomarkers.

A cross-plot of age parameters based on the ratio of the dinosteroid and 28-nordinosteroid series to their corresponding 24-ethyl analogues yielded a positive correlation for the study oils, although significantly wider confidence limits were recorded for the 28-nordinosteroid parameter. Some Triassic oils, from marine shales and carbonates, exhibited similar values for the triaromatic dinosteroid parameter to younger marine oils, and Jurassic marine oils spanned the entire parameter range, so age resolution is best restricted to differentiating Carboniferous-Permian oils (as yet found not to contain dinosteroids) from younger oils, unless local source-rock calibration is possible. Depositional environments could not be differentiated with confidence. Mesozoic-Tertiary lacustrine oils do not always contain detectable triaromatic dinosteroids, and values of their 28-nordinosteroid age parameters can vary quite widely, so even a coarse age attribution for such samples requires care. Values obtained for both age parameters are elevated (ultimately tending towards $100 \%$ ) in oils that have experienced sufficiently severe biodegradation or metamorphism to deplete the less robust compounds routinely used as ratio denominators.

\section{Declaration of Competing Interest}

The authors declare that they have no known competing financial interests or personal relationships that could have appeared to influence the work reported in this paper.

\section{Acknowledgements}

The research did not receive any specific grant from funding agencies in the public, commercial, or not-for-profit sectors. We thank Andy Bishop (associate editor) and an anonymous reviewer for helpful comments that have improved (and extended the scope of) the manuscript. 
Appendix 1. Triaromatic dinosteroid distributions in NSO-1 standard oil replicates

\begin{tabular}{|c|c|c|c|c|c|}
\hline \%TD1 & \%TD2 & \%TD3 & \%TD4 & \%TD5 & \%TD6 \\
\hline 6.41 & 17.46 & 15.46 & 20.08 & 13.67 & 26.92 \\
\hline 6.28 & 17.89 & 15.55 & 19.70 & 13.21 & 27.37 \\
\hline 6.44 & 17.81 & 15.88 & 19.31 & 13.09 & 27.47 \\
\hline 6.16 & 17.51 & 14.92 & 20.00 & 13.51 & 27.89 \\
\hline 6.34 & 18.06 & 14.73 & 19.68 & 13.66 & 27.53 \\
\hline 6.10 & 17.18 & 14.01 & 20.68 & 12.66 & 29.38 \\
\hline 6.19 & 18.01 & 13.92 & 20.44 & 13.37 & 28.07 \\
\hline 6.28 & 17.53 & 14.72 & 20.13 & 13.85 & 27.49 \\
\hline 6.19 & 17.61 & 14.73 & 20.49 & 13.55 & 27.43 \\
\hline 6.34 & 16.97 & 15.25 & 20.19 & 13.53 & 27.71 \\
\hline 6.11 & 18.53 & 15.47 & 19.89 & 13.05 & 26.95 \\
\hline 6.28 & 17.57 & 16.11 & 19.67 & 13.60 & 26.78 \\
\hline 6.53 & 17.26 & 15.58 & 20.95 & 12.84 & 26.84 \\
\hline 6.51 & 17.75 & 15.55 & 20.06 & 13.13 & 27.00 \\
\hline 6.32 & 17.60 & 15.38 & 20.13 & 13.17 & 27.40 \\
\hline 6.46 & 17.51 & 15.32 & 19.15 & 13.24 & 28.34 \\
\hline 6.23 & 17.53 & 15.63 & 19.64 & 13.73 & 27.24 \\
\hline 6.47 & 17.60 & 15.06 & 20.15 & 13.57 & 27.15 \\
\hline 6.12 & 16.83 & 14.43 & 19.89 & 14.32 & 28.42 \\
\hline 6.48 & 17.93 & 14.25 & 20.09 & 13.82 & 27.43 \\
\hline 5.75 & 17.47 & 13.79 & 19.08 & 14.48 & 29.43 \\
\hline 6.38 & 17.55 & 15.53 & 19.79 & 13.30 & 27.45 \\
\hline 6.34 & 17.42 & 14.62 & 20.43 & 13.01 & 28.17 \\
\hline 6.32 & 17.91 & 15.81 & 19.28 & 13.49 & 27.19 \\
\hline 6.22 & 17.79 & 15.07 & 19.21 & 13.32 & 28.38 \\
\hline 6.28 & 18.20 & 14.95 & 19.50 & 13.76 & 27.30 \\
\hline 6.49 & 18.05 & 14.70 & 20.11 & 13.19 & 27.46 \\
\hline 6.67 & 17.64 & 15.59 & 20.31 & 13.33 & 26.46 \\
\hline 6.25 & 18.01 & 14.83 & 20.23 & 12.92 & 27.75 \\
\hline 6.53 & 17.26 & 15.47 & 20.42 & 13.37 & 26.95 \\
\hline 6.30 & 17.31 & 15.38 & 20.19 & 13.03 & 27.78 \\
\hline 6.58 & 18.18 & 15.05 & 19.64 & 13.79 & 26.75 \\
\hline 6.41 & 17.46 & 15.69 & 19.56 & 13.04 & 27.85 \\
\hline 6.34 & 17.89 & 15.44 & 20.55 & 13.60 & 26.18 \\
\hline 5.95 & 17.66 & 15.81 & 20.74 & 13.55 & 26.28 \\
\hline 6.10 & 17.58 & 15.04 & 21.24 & 13.62 & 26.42 \\
\hline 6.36 & 17.80 & 15.47 & 20.23 & 12.61 & 27.54 \\
\hline 6.29 & 17.19 & 15.51 & 20.44 & 13.42 & 27.15 \\
\hline 6.45 & 17.34 & 15.22 & 20.08 & 13.53 & 27.38 \\
\hline 6.18 & 18.12 & 14.61 & 20.47 & 13.22 & 27.40 \\
\hline 6.43 & 17.76 & 15.14 & 19.61 & 12.85 & 28.21 \\
\hline 6.32 & 17.36 & 15.43 & 20.36 & 12.86 & 27.65 \\
\hline 6.67 & 17.51 & 15.54 & 19.47 & 13.68 & 27.13 \\
\hline 6.40 & 17.59 & 15.46 & 19.72 & 13.97 & 26.87 \\
\hline 6.55 & 17.19 & 15.04 & 20.19 & 13.96 & 27.07 \\
\hline 6.87 & 16.58 & 14.18 & 20.07 & 14.39 & 27.92 \\
\hline 6.05 & 17.28 & 15.33 & 18.79 & 14.58 & 27.97 \\
\hline 5.67 & 17.33 & 15.29 & 19.25 & 14.97 & 27.49 \\
\hline 5.76 & 17.59 & 15.50 & 19.06 & 15.29 & 26.81 \\
\hline 6.12 & 18.14 & 15.40 & 18.78 & 15.40 & 26.16 \\
\hline 6.14 & 17.57 & 15.03 & 19.26 & 15.03 & 26.98 \\
\hline 6.15 & 18.00 & 15.15 & 18.44 & 15.04 & 27.22 \\
\hline 6.67 & 17.52 & 15.75 & 19.81 & 13.14 & 27.11 \\
\hline 6.47 & 16.81 & 14.87 & 20.69 & 13.25 & 27.91 \\
\hline 6.12 & 17.41 & 15.40 & 20.25 & 13.50 & 27.32 \\
\hline 6.46 & 17.09 & 15.12 & 19.28 & 13.69 & 28.37 \\
\hline 6.97 & 17.97 & 15.68 & 19.79 & 13.06 & 26.52 \\
\hline 6.97 & 18.27 & 15.87 & 20.28 & 12.77 & 25.85 \\
\hline 6.92 & 18.57 & 16.05 & 19.12 & 13.22 & 26.12 \\
\hline
\end{tabular}

Appendix 2. Triaromatic dinosteroid distributions and age parameters for Norwegian North Sea oils (see Table 1 for compound abbreviations). Oil families after Justwan et al. (2006); C3 = mature equivalent ( $>1 \%$ vitrinite reflectance) of C1. CG = Central Graben, EB $=$ Egersund Basin, NVG $=$ North Viking Graben, SVG $=$ South Viking Graben

\begin{tabular}{|c|c|c|c|c|c|c|c|c|c|c|c|c|c|}
\hline well & $\begin{array}{l}\text { field/ } \\
\text { discovery }\end{array}$ & area & test & depth (mMD) & family & $\begin{array}{l}\% \\
\text { TD1 }\end{array}$ & $\begin{array}{l}\% \\
\text { TD2 }\end{array}$ & $\begin{array}{l}\% \\
\text { TD3 }\end{array}$ & $\begin{array}{l}\% \\
\text { TD4 }\end{array}$ & $\begin{array}{l}\% \\
\text { TD5 }\end{array}$ & $\begin{array}{l}\% \\
\text { TD6 }\end{array}$ & $\begin{array}{l}\Sigma T D 1-6 /(\Sigma T D 1- \\
6+4 M 24 E S+R) \\
\%\end{array}$ & $\begin{array}{l}\text { TnD2 / } \\
(\mathrm{TnD2}+ \\
28 S) \%\end{array}$ \\
\hline $1 / 2-1$ & Blane & CG & DST1 & $3123-37$ & $\mathrm{C} 1$ & 6.20 & 18.94 & 16.80 & 21.31 & 12.85 & 23.90 & 82.13 & 12.59 \\
\hline $1 / 5-2$ & Flyndre & CG & DST4 & $2832-41$ & $\mathrm{C} 1$ & 6.54 & 20.84 & 15.30 & 19.62 & 11.53 & 26.16 & 84.38 & 16.81 \\
\hline $1 / 9-1$ & Tommeliten $\alpha$ & CG & DST1.1 & $3298-312$ & B & 6.22 & 17.87 & 15.66 & 21.08 & 13.86 & 25.30 & 83.56 & 12.10 \\
\hline
\end{tabular}


(continued)

\begin{tabular}{|c|c|c|c|c|c|c|c|c|c|c|c|c|c|}
\hline well & $\begin{array}{l}\text { field/ } \\
\text { discovery }\end{array}$ & area & test & depth (mMD) & family & $\begin{array}{l}\% \\
\text { TD1 }\end{array}$ & $\begin{array}{l}\% \\
\text { TD2 }\end{array}$ & $\begin{array}{l}\% \\
\text { TD3 }\end{array}$ & $\begin{array}{l}\% \\
\text { TD4 }\end{array}$ & $\begin{array}{l}\% \\
\text { TD5 }\end{array}$ & $\begin{array}{l}\% \\
\text { TD6 }\end{array}$ & 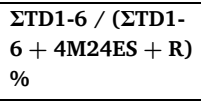 & $\begin{array}{l}\text { TnD2 / } \\
\text { (TnD2 + } \\
28 S) \%\end{array}$ \\
\hline $2 / 2-5$ & Bumblebee & CG & DST1 & $3666-70$ & A & 6.94 & 17.16 & 16.47 & 18.85 & 15.28 & 25.30 & 88.97 & 16.89 \\
\hline $2 / 4-11$ & Espen & CG & DST5 & $3139-46$ & $\mathrm{C} 1$ & 6.12 & 17.21 & 16.76 & 22.08 & 13.82 & 24.01 & 81.68 & 10.22 \\
\hline $2 / 5-7$ & $2 / 5-7$ & CG & PT2 & $3263-87$ & $\mathrm{C} 3$ & 6.35 & 18.39 & 17.73 & 21.57 & 12.37 & 23.58 & 77.97 & 9.45 \\
\hline $2 / 5-11$ & Tjatse & CG & DST1 & $3363-81$ & C3 & 6.06 & 19.09 & 17.58 & 21.06 & 12.27 & 23.94 & 79.71 & 9.90 \\
\hline $2 / 7-4$ & Edda & CG & DST3+6 & $3106-70$ & $\mathrm{C} 1$ & 6.52 & 18.76 & 15.96 & 22.02 & 12.92 & 23.82 & 73.98 & 12.41 \\
\hline $2 / 7-6$ & Eldfisk & CG & DST2 & 3069-78 & B & 6.35 & 17.87 & 15.29 & 20.45 & 13.56 & 26.48 & 84.69 & 12.90 \\
\hline $2 / 7-9$ & Embla & CG & DST3 & 3098-109 & B & 5.83 & 18.25 & 17.18 & 21.75 & 12.43 & 24.56 & 84.56 & 13.02 \\
\hline $3 / 7-4$ & Trym & CG & DST1B & $3440-73$ & G & 5.95 & 15.86 & 16.29 & 22.66 & 12.61 & 26.63 & 73.85 & 7.69 \\
\hline $7 / 8-3$ & Krabbe & CG & DST1 & $3762-67$ & $\mathrm{C} 3$ & 7.12 & 18.31 & 15.59 & 17.29 & 16.95 & 24.75 & 74.40 & 10.94 \\
\hline $7 / 11-3$ & Cod & CG & DST7 & 3086-92 & $\mathrm{C} 3$ & 6.39 & 18.69 & 12.77 & 18.85 & 14.95 & 28.35 & 77.16 & 11.20 \\
\hline $9 / 2-1$ & Yme & EB & DST3 & $3177-210$ & $\mathrm{C} 2$ & 7.45 & 15.95 & 16.16 & 20.46 & 14.27 & 25.71 & 80.02 & 11.39 \\
\hline $9 / 2-6 \mathrm{~S}$ & Yme & $\mathrm{EB}$ & FMT & 4809 & $\mathrm{C} 2$ & 6.27 & 15.74 & 15.60 & 22.42 & 13.37 & 26.60 & 78.56 & 11.35 \\
\hline $15 / 3-4$ & Sigrun & SVG & DST1 & 3789-807 & $\mathrm{C} 3$ & 6.70 & 17.32 & 16.18 & 21.49 & 13.27 & 25.03 & 80.71 & 10.96 \\
\hline $15 / 5-5$ & Glitne & SVG & PT1 & 2154-84 & A & 6.73 & 17.42 & 15.33 & 19.51 & 13.89 & 27.12 & 86.30 & 18.88 \\
\hline $15 / 6-2$ & Gina Krog & SVG & FIT7 & 3606 & B & 7.19 & 17.43 & 16.62 & 20.06 & 13.07 & 25.63 & 86.73 & 18.59 \\
\hline $15 / 9-5$ & Sleipner V & SVG & DST2 & $3588-93$ & $\mathrm{D}$ & 7.06 & 18.65 & 16.33 & 20.16 & 12.30 & 25.50 & 86.11 & 15.61 \\
\hline $\begin{array}{l}\text { 15/ } \\
9-17\end{array}$ & $\begin{array}{l}\text { Sleipner } \varnothing \\
\text { (Loke) }\end{array}$ & SVG & DST2 & $2726-41$ & $\mathrm{E}$ & 7.68 & 20.31 & 14.84 & 21.09 & 11.46 & 24.61 & 84.58 & 10.71 \\
\hline $\begin{array}{l}15 / \\
9-19 \\
\text { A }\end{array}$ & Volve & SVG & DST2A & $3885-88$ & A & 6.23 & 16.83 & 14.86 & 19.45 & 14.64 & 27.98 & 89.44 & 18.97 \\
\hline $\begin{array}{l}15 / \\
12-21\end{array}$ & Grevling & SVG & RCI & 3034.5 & A & 5.85 & 16.86 & 14.79 & 18.92 & 14.91 & 28.67 & 88.17 & 20.30 \\
\hline $\begin{array}{c}16 / 1-8 \\
\mathrm{R}\end{array}$ & Edvard Grieg & SVG & DST1+2 & $1926-59$ & $\mathrm{C} 1$ & 6.26 & 16.63 & 15.66 & 19.98 & 13.61 & 27.86 & 88.19 & 16.03 \\
\hline $16 / 1-9$ & Ivar Aasen & SVG & MDT & 2419.5 & C3 & 6.46 & 15.96 & 16.51 & 21.46 & 13.34 & 26.27 & 72.85 & 9.35 \\
\hline $\begin{array}{l}16 / \\
1-12\end{array}$ & Rolvsnes & SVG & miniDST & 1922.5 & $\mathrm{C} 1$ & 6.09 & 16.10 & 14.80 & 20.24 & 14.47 & 28.29 & 88.20 & 16.92 \\
\hline $\begin{array}{l}16 / \\
2-11 \\
\text { A }\end{array}$ & $\begin{array}{l}\text { Johan } \\
\text { Sverdrup }\end{array}$ & SVG & MDT & 2186 & $\mathrm{C} 1$ & 6.55 & 15.24 & 15.45 & 20.92 & 14.27 & 27.58 & 88.01 & 17.65 \\
\hline $\begin{array}{c}16 / 4-8 \\
S\end{array}$ & Solveig & SVG & MDT & 1942.3 & $\mathrm{C} 1$ & 6.20 & 17.12 & 15.02 & 19.85 & 13.87 & 27.94 & 88.64 & 18.26 \\
\hline $\begin{array}{l}17 / \\
12-1 \\
\mathrm{R}\end{array}$ & Vette & EB & DST1 & $2337-41$ & $\mathrm{C} 1$ & 7.03 & 15.42 & 15.65 & 19.27 & 14.29 & 28.34 & 83.05 & 13.11 \\
\hline $\begin{array}{l}17 / \\
12-2\end{array}$ & Brisling & EB & DST2 & $2157-62$ & B & 6.62 & 16.88 & 15.17 & 20.51 & 13.57 & 27.24 & 84.71 & 12.63 \\
\hline $\begin{array}{l}18 / \\
10-1\end{array}$ & Mackerel & EB & DST1 & $2390-402$ & $\mathrm{D}$ & 6.40 & 14.93 & 15.35 & 21.11 & 15.25 & 26.97 & 82.50 & 12.98 \\
\hline $24 / 9-3$ & Froskelår & SVG & DST2 & $1765-82$ & $\mathrm{C} 1$ & 6.71 & 16.83 & 14.91 & 19.06 & 15.34 & 27.16 & 90.03 & 20.00 \\
\hline $24 / 9-5$ & Volund & SVG & FMT & 2011-18 & G & 5.50 & 18.70 & 15.84 & 20.24 & 14.63 & 25.08 & 84.79 & 13.48 \\
\hline $\begin{array}{c}24 / 9-9 \\
\text { S }\end{array}$ & Bøyla & SVG & MDT & 2221 & $\mathrm{C} 3$ & 6.70 & 16.92 & 15.60 & 19.89 & 13.41 & 27.47 & 90.10 & 20.49 \\
\hline $25 / 1-9$ & Litjklakken & SVG & RFT2 & 2056.5 & $\mathrm{C} 3$ & 7.00 & 19.08 & 16.69 & 22.06 & 12.22 & 22.95 & 79.98 & 7.63 \\
\hline $\begin{array}{l}25 / \\
2-10 \\
S\end{array}$ & Frigg- $\gamma \delta$ & SVG & RFT5 & 2252.5 & $\mathrm{C} 1$ & 6.73 & 17.15 & 16.14 & 20.63 & 13.23 & 26.12 & 83.68 & 12.75 \\
\hline $\begin{array}{l}25 / \\
2-13\end{array}$ & L Frøy & SVG & DST5 & $3343-82$ & G & 6.39 & 16.17 & 14.95 & 20.92 & 14.13 & 27.45 & 75.33 & 8.99 \\
\hline $25 / 5-2$ & Frøy & SVG & DST2 & 3196-201 & G & 6.14 & 16.34 & 15.30 & 21.78 & 13.67 & 26.77 & 82.27 & 12.58 \\
\hline $25 / 5-5$ & Tir & SVG & DST & 2159-70 & A & 6.38 & 16.82 & 13.57 & 21.35 & 14.15 & 27.73 & 87.69 & 17.24 \\
\hline $25 / 7-3$ & Jotun & SVG & DST1 & 2096-107 & G & 5.46 & 19.27 & 15.37 & 18.49 & 14.37 & 27.06 & 81.05 & 10.81 \\
\hline $25 / 7-5$ & Alvheim & SVG & DST1 & 2043-52 & $\mathrm{C} 2$ & 6.93 & 16.86 & 15.36 & 19.28 & 15.01 & 26.56 & 83.75 & 14.18 \\
\hline $25 / 8-1$ & $\begin{array}{l}\text { Balder } \\
\text { (Forseti) }\end{array}$ & SVG & PT & $1755-62$ & $\mathrm{C} 2$ & 6.17 & 17.28 & 16.26 & 18.72 & 15.23 & 26.34 & 92.75 & 26.39 \\
\hline $\begin{array}{c}25 / 8-9 \\
\mathrm{~A}\end{array}$ & Krap & SVG & MDT & 2492.1 & G & 6.47 & 16.88 & 16.18 & 21.39 & 13.41 & 25.66 & 80.99 & 11.33 \\
\hline 8-11 & $\begin{array}{l}\text { Balder } \\
\text { (Ringhorne) }\end{array}$ & SVG & DST1 & 1893-910 & $\mathrm{C} 2$ & 6.22 & 17.45 & 15.59 & 19.74 & 13.96 & 27.04 & 92.25 & 25.15 \\
\hline $\begin{array}{l}25 / \\
8-14 \\
S\end{array}$ & Ringhorne $\varnothing$ & SVG & $\mathrm{RCI}$ & 2596.8 & $\mathrm{C} 1$ & 6.43 & 17.38 & 16.08 & 18.99 & 13.71 & 27.41 & 96.74 & 49.38 \\
\hline $\begin{array}{l}25 / \\
10-8\end{array}$ & Hanz & SVG & DST1 & 2392-98 & $\mathrm{C} 3$ & 5.53 & 19.92 & 13.55 & 19.36 & 12.72 & 28.91 & 85.77 & 13.33 \\
\hline $\begin{array}{l}25 / \\
11-8\end{array}$ & Balder & SVG & DST1 & $1752-67$ & $\mathrm{C} 1$ & 6.32 & 17.02 & 15.20 & 20.24 & 14.35 & 26.87 & 93.21 & 22.96 \\
\hline $\begin{array}{l}25 / \\
11-15\end{array}$ & Grane & SVG & DST1 & $1736-74$ & $\mathrm{C} 1$ & 6.41 & 17.63 & 15.81 & 19.55 & 13.89 & 26.71 & 93.60 & 27.21 \\
\hline $\begin{array}{l}25 / \\
11-16\end{array}$ & Svalin & SVG & RFT & $\begin{array}{l}1774 / \\
1793.5 / \\
1838^{*}\end{array}$ & $\mathrm{C} 3$ & 6.58 & 17.26 & 15.32 & 19.85 & 14.02 & 26.97 & 92.15 & 22.95 \\
\hline $30 / 3-4$ & $\begin{array}{l}\text { Veslefrikk } \\
\text { Veslefrikk }\end{array}$ & $\begin{array}{l}\text { NVG } \\
\text { NVG }\end{array}$ & $\begin{array}{l}\text { DST5 } \\
\text { PT2 }\end{array}$ & $\begin{array}{l}2850-57 \\
4872-94\end{array}$ & $\begin{array}{l}\mathrm{C} 1 \\
\mathrm{C} 3\end{array}$ & $\begin{array}{l}6.49 \\
6.42\end{array}$ & $\begin{array}{l}17.23 \\
16.50\end{array}$ & $\begin{array}{l}16.49 \\
16.06\end{array}$ & $\begin{array}{l}20.74 \\
23.07\end{array}$ & $\begin{array}{l}13.19 \\
12.85\end{array}$ & $\begin{array}{l}25.85 \\
25.11\end{array}$ & $\begin{array}{l}80.90 \\
80.87\end{array}$ & $\begin{array}{r}12.22 \\
9.88\end{array}$ \\
\hline
\end{tabular}


(continued)

\begin{tabular}{|c|c|c|c|c|c|c|c|c|c|c|c|c|c|}
\hline well & $\begin{array}{l}\text { field/ } \\
\text { discovery }\end{array}$ & area & test & depth (mMD) & family & $\begin{array}{l}\% \\
\text { TD1 }\end{array}$ & $\begin{array}{l}\% \\
\text { TD2 }\end{array}$ & $\begin{array}{l}\% \\
\text { TD3 }\end{array}$ & $\begin{array}{l}\% \\
\text { TD4 }\end{array}$ & $\begin{array}{l}\% \\
\text { TD5 }\end{array}$ & $\begin{array}{l}\% \\
\text { TD6 }\end{array}$ & 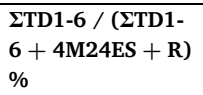 & $\begin{array}{l}\text { TnD2 / } \\
(\text { TnD2 + } \\
28 S) \%\end{array}$ \\
\hline \multicolumn{14}{|l|}{$\begin{array}{l}30 / 3-7 \\
\mathrm{~S}\end{array}$} \\
\hline $30 / 6-1$ & Oseberg & NVG & DST1 & $2320-30$ & $\mathrm{D}$ & 7.62 & 19.64 & 14.83 & 21.24 & 13.23 & 23.45 & 88.24 & 16.80 \\
\hline $\begin{array}{l}30 / \\
6-15\end{array}$ & Oseberg V & NVG & DST2 & $3324-30$ & $\mathrm{C} 1$ & 6.00 & 18.01 & 15.65 & 21.11 & 12.65 & 26.58 & 86.07 & 14.86 \\
\hline $\begin{array}{l}30 / \\
6-16\end{array}$ & Oseberg $\theta$ & NVG & DST2 & $2855-68$ & $\mathrm{D}$ & 6.23 & 17.63 & 15.42 & 20.06 & 12.99 & 27.67 & 86.01 & 14.69 \\
\hline $\begin{array}{l}30 / \\
6-17 \\
\mathrm{R}\end{array}$ & Oseberg & NVG & DST1 & $2402-15$ & $\mathrm{C} 1$ & 6.42 & 17.52 & 16.10 & 20.13 & 12.40 & 27.42 & 86.13 & 15.83 \\
\hline $\begin{array}{l}30 / \\
6-19\end{array}$ & Oseberg Ø & NVG & DST1 & $2945-54$ & $\mathrm{C} 1$ & 6.23 & 17.57 & 17.16 & 20.94 & 13.18 & 24.92 & 81.79 & 13.48 \\
\hline $30 / 7-2$ & Martin Linge & NVG & DST2 & $1766-77$ & $\mathrm{G}$ & 6.15 & 17.77 & 16.17 & 19.13 & 15.95 & 24.83 & 81.30 & 13.01 \\
\hline $30 / 9-1$ & Oseberg & NVG & DST3 & 2689-92 & $\mathrm{C} 2$ & 6.70 & 17.85 & 15.52 & 19.98 & 12.75 & 27.21 & 87.94 & 17.14 \\
\hline $30 / 9-9$ & Oseberg S & NVG & DST1 & 2394-409 & $\mathrm{G}$ & 6.71 & 16.83 & 15.40 & 20.68 & 13.53 & 26.84 & 83.47 & 14.29 \\
\hline $\begin{array}{l}30 / \\
9-10\end{array}$ & Oseberg S & NVG & DST1A & $2757-76$ & $\mathrm{C} 2$ & 6.35 & 18.11 & 15.09 & 20.50 & 13.11 & 26.85 & 89.06 & 18.98 \\
\hline $\begin{array}{l}33 / \\
9-13 \\
S\end{array}$ & Statfjord N & NVG & DST1.1+1.2 & $2758-87$ & $\mathrm{C} 1$ & 6.21 & 16.34 & 14.96 & 21.17 & 14.04 & 27.27 & 83.48 & 13.19 \\
\hline $\begin{array}{l}33 / \\
9-19 \\
S\end{array}$ & Sygna & NVG & MDT & 2701 & $\mathrm{C} 1$ & 6.82 & 16.44 & 15.88 & 20.36 & 13.65 & 26.85 & 82.85 & 12.75 \\
\hline $34 / 4-1$ & Snorre & NVG & DST2 & $2510-36$ & $\mathrm{C} 1$ & 6.03 & 17.65 & 15.75 & 18.99 & 14.97 & 26.59 & 83.02 & 15.49 \\
\hline $34 / 4-5$ & Snorre $\zeta$ & NVG & DST2 & $3463-81$ & $\mathrm{C} 1$ & 5.57 & 17.40 & 16.47 & 19.49 & 15.78 & 25.29 & 78.94 & 12.42 \\
\hline $34 / 7-5$ & Statfjord Ø & NVG & DST1A & $2503-2513$ & $\mathrm{C} 1$ & 6.58 & 17.11 & 15.24 & 19.41 & 14.25 & 27.41 & 85.39 & 14.50 \\
\hline $\begin{array}{l}34 / \\
7-12\end{array}$ & Tordis & NVG & FMT & 2171 & C1 & 6.64 & 16.32 & 15.45 & 20.57 & 13.71 & 27.31 & 85.33 & 14.29 \\
\hline $\begin{array}{l}34 / \\
7-18\end{array}$ & Vigdis & NVG & RFT & 2284.6 & $\mathrm{C} 1$ & 6.72 & 16.74 & 14.07 & 20.04 & 14.71 & 27.72 & 85.90 & 14.60 \\
\hline $\begin{array}{l}34 / \\
7-22\end{array}$ & Tordis $\varnothing$ & NVG & FMT2B & 2246.3 & $\mathrm{C} 1$ & 6.54 & 17.09 & 15.82 & 20.99 & 13.50 & 26.05 & 85.87 & 14.39 \\
\hline $\begin{array}{l}34 / \\
7-29 \\
\text { SR }\end{array}$ & $\begin{array}{l}\text { Vigdis (H- } \\
\text { North) }\end{array}$ & NVG & PT1 & 2704-16 & C1 & 5.88 & 17.52 & 15.34 & 20.67 & 13.06 & 27.53 & 84.94 & 14.71 \\
\hline $\begin{array}{c}34 / 8-4 \\
S\end{array}$ & Visund & NVG & DST1 & $3062-79$ & C3 & 6.46 & 19.09 & 18.80 & 19.82 & 14.10 & 21.73 & 78.19 & 10.07 \\
\hline $\begin{array}{l}34 / \\
10-33\end{array}$ & Gullfaks S & NVG & DST2.1 & $3279-307$ & G & 6.25 & 16.59 & 17.03 & 22.41 & 12.72 & 25.00 & 80.35 & 10.43 \\
\hline $\begin{array}{l}34 / \\
10-34\end{array}$ & Gullfaks V & NVG & DST1 & 1994-2001 & $\mathrm{C} 1$ & 6.18 & 17.47 & 15.12 & 20.66 & 13.74 & 26.84 & 85.68 & 13.67 \\
\hline $\begin{array}{l}34 / \\
10-38 \\
\text { S }\end{array}$ & $\begin{array}{l}\text { Gullfaks S } \\
\text { (Rimfaks) }\end{array}$ & NVG & DST1B & $3561-70$ & G & 6.27 & 17.71 & 15.50 & 21.28 & 13.04 & 26.20 & 78.78 & 10.13 \\
\hline $35 / 9-7$ & Nova & NVG & MDT & 2626.2 & $\mathrm{C} 1$ & 5.73 & 15.20 & 17.18 & 22.03 & 12.78 & 27.09 & 81.73 & 12.05 \\
\hline $\begin{array}{l}35 / \\
11-4\end{array}$ & Fram & NVG & DST2 & $2286-93$ & G & 6.81 & 18.69 & 16.71 & 20.17 & 12.50 & 25.12 & 80.40 & 10.13 \\
\hline
\end{tabular}

Appendix 3. Triaromatic dinosteroid distributions and age parameters for oils from various areas of the world defined by their source age and depositional environment (see Table 1 for compound abbreviations)

\begin{tabular}{|c|c|c|c|c|c|c|c|c|c|c|}
\hline age & environment & location & $\begin{array}{l}\% \\
\text { TD1 }\end{array}$ & $\begin{array}{l}\% \\
\text { TD2 }\end{array}$ & $\begin{array}{l}\% \\
\text { TD3 }\end{array}$ & $\begin{array}{l}\% \\
\text { TD4 }\end{array}$ & $\begin{array}{l}\% \\
\text { TD5 }\end{array}$ & $\begin{array}{l}\% \\
\text { TD6 }\end{array}$ & $\Sigma T D 1-6 /(\Sigma T D 1-6+4 M 24 E S+R) \%$ & TnD2 / (TnD2 + 28S) \% \\
\hline Tertiary & lacustrine & SE Asia & 7.58 & 16.72 & 16.25 & 22.03 & 11.86 & 25.55 & 35.86 & 0.00 \\
\hline Tertiary & marine & E Europe & 7.07 & 15.83 & 15.53 & 18.27 & 14.46 & 28.84 & 78.46 & 14.57 \\
\hline Tertiary & marine & E Europe & 7.42 & 16.28 & 15.95 & 19.20 & 14.27 & 26.89 & 82.07 & 16.96 \\
\hline Tertiary & marine & E Europe & 7.34 & 16.56 & 14.51 & 19.57 & 14.38 & 27.64 & 80.98 & 18.13 \\
\hline Tertiary & marine & E Europe & 7.48 & 15.92 & 15.01 & 19.10 & 14.50 & 27.99 & 79.39 & 16.75 \\
\hline Tertiary & marine & E Europe & 7.14 & 17.64 & 15.15 & 19.19 & 14.06 & 26.82 & 86.62 & 18.29 \\
\hline Tertiary & marine & E Europe & 7.42 & 17.53 & 15.54 & 18.82 & 13.98 & 26.72 & 82.99 & 18.31 \\
\hline Tertiary & marine & E Europe & 7.63 & 15.63 & 15.16 & 19.85 & 15.38 & 26.35 & 78.64 & 17.50 \\
\hline Tertiary & marine & E Europe & 7.95 & 16.50 & 14.56 & 18.87 & 14.74 & 27.38 & 79.29 & 17.27 \\
\hline Tertiary & marine & E Europe & 7.60 & 16.33 & 16.34 & 19.03 & 15.08 & 25.62 & 84.63 & 16.21 \\
\hline Tertiary & marine & E Europe & 7.46 & 19.06 & 17.01 & 21.74 & 12.38 & 22.35 & 85.55 & 17.16 \\
\hline Tertiary & marine & E Europe & 7.15 & 14.56 & 16.03 & 20.97 & 14.22 & 27.07 & 86.22 & 16.26 \\
\hline Tertiary & marine & E Europe & 7.10 & 15.93 & 16.61 & 19.93 & 14.17 & 26.26 & 89.23 & 19.08 \\
\hline Tertiary & marine & N America & 6.25 & 21.26 & 15.09 & 17.99 & 13.48 & 25.93 & 87.21 & 13.33 \\
\hline Tertiary & marine & W Europe & 8.93 & 20.17 & 13.85 & 17.35 & 13.49 & 26.21 & 83.44 & 24.51 \\
\hline Tertiary & marine & W Europe & 8.21 & 17.76 & 16.65 & 21.11 & 13.07 & 23.20 & 76.03 & 12.79 \\
\hline Tertiary & marine & - & 7.18 & 16.37 & 16.12 & 18.51 & 14.61 & 27.20 & 82.88 & 19.84 \\
\hline
\end{tabular}




\begin{tabular}{|c|c|c|c|c|c|c|c|c|c|c|}
\hline age & environment & location & $\begin{array}{l}\% \\
\text { TD1 }\end{array}$ & $\begin{array}{l}\% \\
\text { TD2 }\end{array}$ & $\begin{array}{l}\% \\
\text { TD3 }\end{array}$ & $\begin{array}{l}\% \\
\text { TD4 }\end{array}$ & $\begin{array}{l}\% \\
\text { TD5 }\end{array}$ & $\begin{array}{l}\% \\
\text { TD6 }\end{array}$ & $\Sigma T D 1-6 /(\Sigma T D 1-6+4 M 24 E S+R) \%$ & TnD2 / (TnD2 + 28S) \% \\
\hline Tertiary & transitional & N Africa & 7.55 & 20.67 & 15.26 & 19.02 & 13.24 & 24.25 & 78.51 & 15.85 \\
\hline Tertiary & transitional & - & 7.33 & 15.82 & 13.94 & 19.30 & 16.09 & 27.52 & 76.64 & 11.11 \\
\hline L Cretaceous & carbonate & - & 7.27 & 15.99 & 16.26 & 20.35 & 13.81 & 26.34 & 84.50 & 19.76 \\
\hline L Cretaceous & lacustrine & S America & 6.67 & 19.04 & 14.19 & 17.20 & 12.93 & 29.97 & 93.70 & 36.81 \\
\hline L Cretaceous & marine & N Africa & 5.38 & 17.25 & 13.33 & 20.06 & 16.76 & 27.22 & 80.66 & 15.13 \\
\hline L Cretaceous & marine & N Africa & 5.61 & 16.59 & 13.37 & 19.21 & 17.54 & 27.68 & 81.36 & 15.56 \\
\hline L Cretaceous & marine & N Africa & 5.60 & 17.09 & 13.54 & 19.19 & 16.92 & 27.65 & 81.77 & 16.22 \\
\hline L Cretaceous & marine & $\mathrm{N}$ Africa & 5.52 & 17.82 & 12.67 & 20.64 & 15.56 & 27.79 & 79.82 & 13.68 \\
\hline L Cretaceous & marine & N Africa & 5.66 & 17.52 & 12.64 & 19.87 & 16.01 & 28.30 & 81.98 & 15.56 \\
\hline L Cretaceous & marine & N Africa & 5.41 & 17.01 & 13.16 & 19.41 & 17.07 & 27.94 & 81.97 & 14.96 \\
\hline L Cretaceous & marine & N Africa & 5.52 & 16.97 & 13.21 & 20.12 & 16.91 & 27.27 & 79.06 & 14.29 \\
\hline L Cretaceous & marine & N Africa & 5.55 & 17.01 & 13.19 & 20.52 & 16.76 & 26.99 & 80.11 & 15.03 \\
\hline L Cretaceous & marine & - & 5.64 & 17.64 & 13.64 & 19.27 & 16.91 & 26.91 & 74.83 & 13.09 \\
\hline L Cretaceous & marine & - & 6.18 & 16.05 & 15.33 & 20.87 & 14.29 & 27.29 & 84.99 & 14.74 \\
\hline L Cretaceous & marl & - & 5.81 & 16.51 & 15.33 & 19.04 & 14.32 & 28.98 & 70.87 & 3.72 \\
\hline L Cretaceous & marl & - & 5.76 & 16.79 & 14.87 & 20.62 & 13.83 & 28.14 & 84.30 & 14.00 \\
\hline M Cretaceous & carbonate & Middle East & 5.96 & 15.64 & 14.88 & 20.48 & 14.90 & 28.15 & 84.28 & 16.33 \\
\hline M Cretaceous & carbonate & Middle East & 5.72 & 17.73 & 16.23 & 19.61 & 14.04 & 26.68 & 81.45 & 11.02 \\
\hline M Cretaceous & carbonate & Middle East & 6.24 & 17.98 & 14.73 & 18.88 & 14.71 & 27.46 & 83.03 & 13.40 \\
\hline M Cretaceous & carbonate & Middle East & 5.54 & 15.61 & 16.89 & 20.23 & 15.00 & 26.74 & 70.15 & 5.77 \\
\hline M Cretaceous & marine & N America & 7.38 & 17.83 & 15.99 & 20.33 & 13.29 & 25.18 & 75.29 & 12.72 \\
\hline M Cretaceous & marine & N America & 6.54 & 17.10 & 17.35 & 21.88 & 14.25 & 22.88 & 65.62 & 12.56 \\
\hline E Cretaceous & carbonate & Middle East & 5.52 & 16.55 & 15.09 & 20.82 & 14.37 & 27.66 & 77.22 & 9.21 \\
\hline E Cretaceous & lacustrine & S America & 5.65 & 17.19 & 17.74 & 21.38 & 12.59 & 25.46 & 74.11 & 27.82 \\
\hline E Cretaceous & lacustrine & S America & 5.59 & 17.07 & 15.89 & 22.77 & 12.27 & 26.41 & 74.05 & 25.40 \\
\hline E Cretaceous & lacustrine & S America & 5.72 & 17.18 & 15.58 & 22.52 & 13.11 & 25.90 & 73.61 & 22.99 \\
\hline E Cretaceous & lacustrine & S America & 5.84 & 16.47 & 17.32 & 20.70 & 13.61 & 26.06 & 74.23 & 25.65 \\
\hline E Cretaceous & lacustrine & S America & 6.01 & 16.18 & 17.49 & 21.44 & 13.33 & 25.56 & 78.88 & 18.68 \\
\hline E Cretaceous & lacustrine & S America & 6.08 & 16.67 & 17.93 & 20.38 & 13.82 & 25.12 & 73.97 & 25.00 \\
\hline Cretaceous & carbonate & Arabia & 7.29 & 16.07 & 14.91 & 19.47 & 14.25 & 28.00 & 84.29 & 18.99 \\
\hline Cretaceous & carbonate & Arabia & 7.20 & 16.12 & 15.63 & 19.23 & 14.32 & 27.50 & 84.63 & 18.75 \\
\hline Cretaceous & carbonate & Arabia & 7.08 & 17.77 & 15.59 & 20.14 & 13.98 & 25.44 & 73.10 & 11.87 \\
\hline Cretaceous & lacustrine & N Africa & 5.47 & 20.96 & 15.72 & 19.93 & 10.67 & 27.26 & 70.15 & 3.11 \\
\hline Cretaceous & lacustrine & N Africa & 6.26 & 20.54 & 15.68 & 19.50 & 11.86 & 26.16 & 70.13 & 4.04 \\
\hline Cretaceous & lacustrine & N Africa & 6.43 & 18.18 & 15.19 & 20.07 & 12.73 & 27.40 & 80.92 & 27.45 \\
\hline Cretaceous & marine & C America & 7.16 & 17.80 & 15.15 & 19.58 & 13.79 & 26.52 & 86.37 & 17.24 \\
\hline Cretaceous & marine & C America & 7.18 & 16.93 & 16.06 & 19.62 & 14.48 & 25.73 & 85.94 & 16.67 \\
\hline Cretaceous & marine & C America & 7.02 & 17.50 & 15.70 & 19.53 & 14.40 & 25.85 & 87.35 & 16.37 \\
\hline Cretaceous & marine & C America & 7.17 & 17.74 & 14.96 & 19.15 & 14.15 & 26.83 & 84.72 & 15.56 \\
\hline Cretaceous & marine & C America & 6.79 & 17.15 & 14.75 & 20.07 & 15.14 & 26.10 & 84.85 & 14.85 \\
\hline Cretaceous & marine & C America & 6.89 & 16.46 & 16.24 & 19.55 & 14.03 & 26.83 & 86.96 & 16.67 \\
\hline Cretaceous & marine & C America & 6.85 & 17.92 & 15.90 & 21.67 & 13.66 & 24.00 & 77.54 & 11.40 \\
\hline Cretaceous & marine & N Africa & 6.67 & 17.43 & 16.17 & 19.30 & 13.41 & 27.01 & 79.50 & 15.06 \\
\hline Cretaceous & marine & N Africa & 6.57 & 18.30 & 15.12 & 18.94 & 13.89 & 27.18 & 79.19 & 14.61 \\
\hline Cretaceous & marine & N Africa & 6.55 & 18.97 & 15.84 & 18.38 & 13.60 & 26.67 & 79.02 & 15.58 \\
\hline Cretaceous & marl & - & 5.96 & 16.38 & 15.18 & 19.40 & 15.10 & 27.98 & 88.40 & 19.21 \\
\hline Cretaceous & transitional & C America & 6.60 & 16.98 & 15.64 & 19.26 & 13.94 & 27.58 & 67.37 & 7.08 \\
\hline Cretaceous & transitional & N Africa & 7.55 & 17.99 & 16.08 & 21.38 & 12.99 & 24.01 & 77.38 & 17.00 \\
\hline Cretaceous & transitional & N Africa & 7.24 & 18.19 & 16.61 & 20.44 & 13.60 & 23.91 & 77.12 & 17.24 \\
\hline Cretaceous & transitional & N Africa & 7.22 & 18.30 & 16.24 & 21.27 & 12.95 & 24.02 & 77.08 & 16.09 \\
\hline Cretaceous & transitional & N Africa & 7.62 & 20.43 & 15.46 & 19.25 & 12.93 & 24.32 & 75.79 & 17.90 \\
\hline Cretaceous & transitional & N Africa & 7.73 & 22.88 & 14.70 & 18.96 & 12.14 & 23.59 & 76.42 & 17.62 \\
\hline Cretaceous & transitional & N Africa & 7.96 & 19.96 & 15.55 & 19.96 & 13.35 & 23.21 & 68.96 & 18.52 \\
\hline Cretaceous & transitional & N Africa & 8.40 & 19.77 & 15.16 & 19.62 & 13.16 & 23.89 & 67.97 & 18.04 \\
\hline L Jurassic & marine & Arabia & 6.74 & 15.65 & 15.02 & 20.59 & 12.23 & 29.77 & 70.96 & 7.59 \\
\hline L Jurassic & marine & Arabia & 5.82 & 15.84 & 16.49 & 20.80 & 11.10 & 29.96 & 66.24 & 6.25 \\
\hline L Jurassic & marine & Arabia & 6.32 & 15.03 & 16.88 & 22.66 & 9.80 & 29.30 & 66.19 & 7.21 \\
\hline L Jurassic & marine & Arabia & 5.65 & 16.65 & 16.13 & 22.30 & 10.26 & 29.01 & 65.46 & 6.10 \\
\hline L Jurassic & marine & Arabia & 6.34 & 15.93 & 16.01 & 20.44 & 14.03 & 27.26 & 75.34 & 9.56 \\
\hline L Jurassic & marine & C America & 6.46 & 15.29 & 15.24 & 19.95 & 14.72 & 28.35 & 73.79 & 11.75 \\
\hline L Jurassic & marine & C America & 6.74 & 15.00 & 15.46 & 21.12 & 14.88 & 26.80 & 73.43 & 11.99 \\
\hline L Jurassic & marine & C America & 6.87 & 15.87 & 15.53 & 20.02 & 14.85 & 26.85 & 74.13 & 11.16 \\
\hline L Jurassic & marine & C America & 6.86 & 15.77 & 15.40 & 19.76 & 14.47 & 27.74 & 73.20 & 10.41 \\
\hline L Jurassic & marine & N America & 5.62 & 17.71 & 15.23 & 19.22 & 13.07 & 29.16 & 96.76 & 32.26 \\
\hline L Jurassic & marine & N America & 6.83 & 18.17 & 17.05 & 21.90 & 11.88 & 24.17 & 89.42 & 21.62 \\
\hline L Jurassic & marine & N America & 6.41 & 17.59 & 17.39 & 19.89 & 12.54 & 26.17 & 85.13 & 14.86 \\
\hline L Jurassic & marine & N America & 6.91 & 17.59 & 14.92 & 19.35 & 13.73 & 27.50 & 89.00 & 18.79 \\
\hline L Jurassic & marine & N America & 7.08 & 17.28 & 17.14 & 24.29 & 12.03 & 22.17 & 80.64 & 16.60 \\
\hline L Jurassic & marine & N America & 6.70 & 19.22 & 14.20 & 18.07 & 12.71 & 29.10 & 89.42 & 17.47 \\
\hline L Jurassic & marine & N America & 6.88 & 17.56 & 15.12 & 19.78 & 13.20 & 27.45 & 90.78 & 21.10 \\
\hline L Jurassic & marine & N America & 7.06 & 17.17 & 15.99 & 20.39 & 13.59 & 25.79 & 85.09 & 19.05 \\
\hline L Jurassic & marine & N America & 7.09 & 17.36 & 15.12 & 19.81 & 13.95 & 26.66 & 89.08 & 18.80 \\
\hline L Jurassic & marine & N America & 6.62 & 17.28 & 15.53 & 19.29 & 13.66 & 27.62 & 90.43 & 18.73 \\
\hline L Jurassic & marine & N America & 9.54 & 16.97 & 14.74 & 18.91 & 13.28 & 26.56 & 77.81 & 12.18 \\
\hline L Jurassic & marine & N America & 6.82 & 17.48 & 15.29 & 18.96 & 13.56 & 27.89 & 90.33 & 18.51 \\
\hline
\end{tabular}


(continued)

\begin{tabular}{|c|c|c|c|c|c|c|c|c|c|c|}
\hline age & environment & location & $\begin{array}{l}\text { \% } \\
\text { TD1 }\end{array}$ & $\begin{array}{l}\text { \% } \\
\text { TD2 }\end{array}$ & $\begin{array}{l}\text { \% } \\
\text { TD3 }\end{array}$ & $\begin{array}{l}\text { \% } \\
\text { TD4 }\end{array}$ & $\begin{array}{l}\% \\
\text { TD5 }\end{array}$ & $\begin{array}{l}\% \\
\text { TD6 }\end{array}$ & 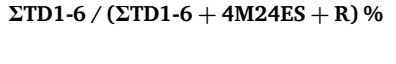 & TnD2 / (TnD2 + 28S) \% \\
\hline L Jurassic & marine & N America & 6.53 & 17.52 & 15.23 & 19.37 & 13.60 & 27.76 & 90.15 & 19.72 \\
\hline L Jurassic & marine & $\mathrm{N}$ America & 6.68 & 17.95 & 15.16 & 19.31 & 13.83 & 27.08 & 90.15 & 19.78 \\
\hline L Jurassic & marine & N America & 6.77 & 16.62 & 15.56 & 19.56 & 13.98 & 27.51 & 88.69 & 16.70 \\
\hline L Jurassic & marine & N America & 6.85 & 16.78 & 15.11 & 18.71 & 14.21 & 28.34 & 89.28 & 16.92 \\
\hline L Jurassic & marine & $\mathrm{N}$ America & 6.62 & 17.81 & 15.27 & 19.99 & 13.20 & 27.12 & 85.55 & 14.43 \\
\hline L Jurassic & marine & N America & 6.55 & 18.04 & 16.02 & 20.15 & 13.16 & 26.09 & 88.23 & 16.68 \\
\hline L Jurassic & marine & $\mathrm{N}$ America & 6.32 & 16.79 & 15.99 & 20.11 & 13.35 & 27.44 & 86.74 & 17.11 \\
\hline L Jurassic & marine & $\mathrm{N}$ America & 6.69 & 17.60 & 15.45 & 19.86 & 13.91 & 26.49 & 90.80 & 22.88 \\
\hline L Jurassic & marine & N America & 6.26 & 17.50 & 16.30 & 19.35 & 13.51 & 27.08 & 88.50 & 17.21 \\
\hline L Jurassic & marine & $\mathrm{N}$ America & 6.14 & 17.15 & 15.36 & 19.37 & 13.84 & 28.13 & 89.85 & 17.69 \\
\hline L Jurassic & marine & $\mathrm{N}$ America & 6.40 & 17.18 & 16.96 & 21.03 & 13.41 & 25.01 & 79.24 & 11.94 \\
\hline L Jurassic & marine & N America & 6.46 & 17.08 & 15.76 & 19.71 & 13.57 & 27.43 & 90.58 & 24.11 \\
\hline L Jurassic & marine & $\mathrm{N}$ America & 6.12 & 16.54 & 17.00 & 20.81 & 13.54 & 25.99 & 86.83 & 17.30 \\
\hline L Jurassic & marine & N America & 6.57 & 17.15 & 15.27 & 19.35 & 13.92 & 27.75 & 88.56 & 19.52 \\
\hline L Jurassic & marine & N America & 6.29 & 17.66 & 15.61 & 19.21 & 13.64 & 27.60 & 89.02 & 18.74 \\
\hline L Jurassic & marine & $\mathrm{N}$ America & 6.13 & 17.35 & 16.98 & 20.53 & 13.33 & 25.68 & 84.17 & 21.26 \\
\hline L Jurassic & marine & $\mathrm{N}$ America & 6.32 & 16.32 & 16.33 & 19.53 & 13.97 & 27.53 & 84.50 & 15.51 \\
\hline L Jurassic & marine & N America & 7.04 & 16.93 & 16.46 & 20.71 & 12.93 & 25.94 & 87.49 & 18.15 \\
\hline L Jurassic & marine & - & 5.82 & 16.57 & 15.04 & 19.56 & 15.04 & 27.97 & 86.69 & 18.83 \\
\hline L Jurassic & marine & - & 6.48 & 17.72 & 15.50 & 18.70 & 14.19 & 27.40 & 82.42 & 10.38 \\
\hline L Jurassic & marine & - & 7.29 & 17.20 & 15.60 & 20.99 & 12.97 & 25.95 & 70.72 & 8.03 \\
\hline L Jurassic & marl & - & 5.81 & 16.03 & 15.33 & 20.09 & 14.40 & 28.34 & 76.81 & 11.17 \\
\hline E Jurassic & marine & W Europe & 7.04 & 17.34 & 16.18 & 20.48 & 13.66 & 25.30 & 81.75 & 17.62 \\
\hline E Jurassic & marine & W Europe & 6.73 & 17.03 & 15.34 & 19.81 & 13.94 & 27.15 & 86.19 & 19.67 \\
\hline E Jurassic & marine & W Europe & 6.69 & 18.31 & 15.25 & 19.17 & 13.10 & 27.48 & 83.22 & 15.61 \\
\hline E Jurassic & marine & W Europe & 6.11 & 16.24 & 15.47 & 20.43 & 14.68 & 27.06 & 83.23 & 17.76 \\
\hline E Jurassic & marine & W Europe & 6.24 & 15.94 & 15.45 & 20.81 & 14.52 & 27.05 & 83.53 & 18.67 \\
\hline E Jurassic & marine & W Europe & 5.65 & 16.51 & 13.41 & 21.03 & 14.61 & 28.79 & 81.11 & 15.56 \\
\hline E Jurassic & marine & W Europe & 5.34 & 16.69 & 13.75 & 20.36 & 15.15 & 28.70 & 85.99 & 15.87 \\
\hline E Jurassic & marine & W Europe & 6.33 & 16.92 & 15.32 & 19.97 & 13.57 & 27.90 & 82.46 & 15.52 \\
\hline E Jurassic & marine & W Europe & 6.36 & 17.15 & 15.67 & 19.73 & 14.04 & 27.05 & 85.15 & 18.18 \\
\hline E Jurassic & marine & W Europe & 6.29 & 16.58 & 15.12 & 19.19 & 14.12 & 28.70 & 84.67 & 17.51 \\
\hline E Jurassic & marine & W Europe & 6.53 & 15.15 & 16.15 & 22.05 & 13.07 & 27.04 & 68.49 & 7.71 \\
\hline E Jurassic & marine & W Europe & 6.56 & 15.85 & 15.30 & 22.50 & 13.11 & 26.68 & 69.41 & 6.39 \\
\hline E Jurassic & marine & W Europe & 6.42 & 15.18 & 15.64 & 21.79 & 12.94 & 28.03 & 69.56 & 8.14 \\
\hline E Jurassic & marine & W Europe & 7.53 & 16.65 & 16.30 & 20.99 & 12.93 & 25.60 & 68.88 & 7.01 \\
\hline E Jurassic & marine & W Europe & 6.66 & 15.34 & 15.95 & 22.87 & 12.88 & 26.29 & 69.53 & 6.65 \\
\hline E Jurassic & marine & W Europe & 6.42 & 15.15 & 15.95 & 21.84 & 13.81 & 26.83 & 70.08 & 7.00 \\
\hline E Jurassic & marine & W Europe & 7.18 & 15.30 & 15.11 & 22.57 & 12.97 & 26.87 & 67.85 & 6.60 \\
\hline E Jurassic & marine & W Europe & 6.15 & 15.83 & 16.95 & 21.23 & 13.50 & 26.35 & 67.80 & 6.64 \\
\hline E Jurassic & marine & W Europe & 6.51 & 15.26 & 15.35 & 23.07 & 12.84 & 26.98 & 68.73 & 6.25 \\
\hline E Jurassic & marine & - & 5.61 & 19.16 & 14.02 & 18.46 & 14.14 & 28.62 & 84.09 & 12.51 \\
\hline L Triassic & carbonate & W Europe & 6.57 & 16.23 & 16.17 & 19.08 & 14.88 & 27.08 & 78.90 & 9.03 \\
\hline L Triassic & carbonate & W Europe & 6.64 & 15.78 & 16.54 & 18.73 & 14.81 & 27.50 & 78.89 & 9.37 \\
\hline L Triassic & carbonate & W Europe & 6.18 & 16.31 & 16.10 & 18.75 & 15.05 & 27.62 & 78.07 & 8.54 \\
\hline L Triassic & marine & W Europe & 7.60 & 17.50 & 16.10 & 20.41 & 13.36 & 25.02 & 83.59 & 17.02 \\
\hline Triassic & carbonate & & 6.08 & 16.48 & 13.76 & 18.88 & 15.36 & 29.44 & 67.64 & 3.61 \\
\hline
\end{tabular}

\section{References}

Ando, T., Sawada, K., Okano, K., Takashima, R., Nishi, H., 2017. Marine primary producer community during the mid-Cretaceous oceanic anoxic events (OAEs) 1a, 1b and $1 \mathrm{~d}$ in the Vocontian Basin (SE France) evaluated from triaromatic steroids in sediments. Organic Geochemistry 106, 13-24.

Annenkova, N.V., Hansen, G., Rengefors, K., 2020. Closely related dinoflagellate species in vastly different habitats - an example of a marine-freshwater transition. European Journal of Phycology 55 (4), 478-489.

Bao, J., Zhu, C., Wang, Z., 2018. Typical end-member oil derived from Cambrian-Lower Ordovician source rocks in the Tarim Basin, NW China. Petroleum Exploration and Development 45 (6), 1177-1188.

Barbanti, S.M., Moldowan, J.M., Watt, D.S., Kolaczkowska, E., 2011. New triaromatic steroids distinguish Paleozoic from Mesozoic oil. Organic Geochemistry 42 (4), 409-424.

Beach, F., Peakman, T.M., Abbott, G.D., Sleeman, R., Maxwell, J.R., 1989. Laboratory thermal alteration of triaromatic steroid hydrocarbons. Organic Geochemistry 14 (1), 109-111.

Bennett, B., Jiang, C., 2021. Oil-source and oil-oil correlations and the origin of the heavy oil and bitumen accumulations in Norther Alberta, Canada. Organic Geochemistry 153, 104199.

Brocks, J.J., Buick, R., Logan, G.A., Summons, R.E., 2003. Composition and syngeneity of molecular fossils from the 2.78 to 2.45 billion-year-old Mount Bruce Supergroup, Pilbara Craton, Western Australia. Geochimica et Cosmochimica Acta 67 (22), 4289-4319.
Brocks, J.J., Jarrett, J.M., Sirantoine, E., Kenig, F., Moczydlowska, M., Porter, S., Hope, J., 2015. Early sponges and toxic protists: possible sources of cryostane, and age diagnostic biomarker antedating Sturtian Snowball Earth. Geobiology 14, $129-149$.

Cermeño, P., 2016. The geological story of marine diatoms and the last generation of fossil fuels. Perspectives in Phycology 3 (2), 53-60.

Disnar, J.R., Harouna, M., 1994. Biological origin of tetracyclic diterpanes, n-alkanes and other biomarkers found in Lower Carboniferous Gondwana coals (Niger). Organic Geochemistry 21 (2), 143-152.

Fensome, R.A., Saldarriaga, J.F., Taylor, "F.J.R., 1999. Dinoflagellate phylogeny revisited: reconciling morphological and molecular based phylogenies. Grana 38 (23), 66-80.

French, K.L., Hallmann, C., Hope, J.M., Schoon, P.L., Zumberge, J.A., Hoshino, Y., Peters, C.A., George, S.C., Love, G.D., Brocks, J.J., Buick, R., Summons, R.E., 2015. Reappraisal of hydrocarbon biomarkers in Archean rocks. Proceedings of the National Academy of Sciences 112 (19), 5915-5920.

Garrigues, P., Ewald, M., 1983. Natural occurrence of 4-methyl-phenanthrene in petroleums and recent marine sediments. Organic Geochemistry 5 (2), 53-56.

Grosjean, E., Love, G.D., Stalvies, C., Fike, D.A., Summons, R.E., 2009. Origin of petroleum in the Neoproterozoic-Cambrian South Oman Salt Basin. Organic Geochemistry 40 (1), 87-110.

Holba, A.G., Tegelaar, E.W., Huizinga, B.J., Moldowan, J.M., Singletary, M.S. McCaffrey, M.A., Dzou, L.I.P., 1998. 24-Norcholestanes as age-sensitive molecular fossils. Geology 26 (9), 783. https://doi.org/10.1130/0091-7613(1998)026<0783: NAASMF $>2.3 . \mathrm{CO} ; 2$. 
Holba, A.G., Dzou, L.I., Wood, G.D., Ellis, L., Adam, P., Schaeffer, P., Albrecht, P.,

Greene, T., Hughes, W.B., 2003. Application of tetracyclic polyprenoids as indicators of input from fresh-brackish water environments. Organic Geochemistry 34 (3), $441-469$.

Huang, H., Zhang, S., Su, J., 2016. Palaeozoic oil-source correlation in the Tarim Basin, NW China: a review. Organic Geochemistry 94, 32-46.

Javaux, E.J., Marshal, C.P., 2006. A new approach in deciphering early protist paleobiology and evolution: Combined microscopy and microchemistry of single Proterozoic acritarchs. Review of Palaeobotany and Palynology 139 (1-4), 1-15.

Janouškovec, J., Gavelis, G.S., Burki, F., Dinh, D., Bachvaroff, T.R., Gornik, S.G., Bright, K.J., Imanian, B., Strom, S.L., Delwiche, C.F., Waller, R.F., Fensome, R.A., Leander, B.S., Rohwer, F.L., Saldarriaga, J.F., 2017. Major transitions in dinoflagellate evolution unveiled by phylotranscriptomics. Proceedings of the National Academy of Sciences 114 (2), E171-E180.

Justwan, H., Dahl, B., Isaksen, G.H., 2006. Geochemical characterization and genetic origin of oils and condensates in the South Viking Graben, Norway. Marine and Petroleum Geology 23, 213-239.

Keym, M., Dieckmann, V., Horsfield, B., Erdmann, M., Galimberti, R., Kua, L.-C., Leith, L., Podlaha, O., 2006. Source rock heterogeneity of the Upper Jurassic Draupne Formation, North Viking Graben, and its relevance to petroleum generation studies. Organic Geochemistry 37 (2), 220-243.

Killops, S.D., 1986. The influence of operating conditions on the evaluation of biological marker compound distributions in petroleum geochemistry by gas chromatography and gas chromatography/mass spectrometry. Analytica Chimica Acta 183, 105-128.

Killops, S.D., Woolhouse, A.D., Weston, R.J., Cook, R.A., 1994. A geochemical appraisal of oil generation in the Taranaki Basin, New Zealand. AAPG Bulletin 78, 1560-1585.

Killops, S.D., Nytoft, H.P., di Primio, R., 2019. Biodegradative production and destruction of norhopanes - An example from residual oil in a Paleogene paleomigration conduit on the Utsira High, Norwegian North Sea. Organic Geochemistry 138, 103906. https://doi.org/10.1016/j.orggeochem.2019.103906.

Knoll, A.H., Summons, R.E., Waldbauer, J.R., Zumberge, J.E., 2007. The geological succession of primary producers in the oceans. In: Falkowski, P., Knoll, A.H. (Eds.), Evolution of Primary Producers in the Sea. Elsevier, pp. 133-163.

Li, M., Wang, T.-G., Lillis, P.G., Wang, C., Shi, S., 2012. The significance of 24-norcholestanes, triaromatic steroids and dinosteroids in oils and Cambrian-Ordovician source rocks from the cratonic region of the Tarim Basin, NW China. Applied Geochemistry 27 (8), 1643-1654.

Lichtfouse, E., 1989. Nouveaux stéroïdes aromatiques fossils. PhD thesis. Pasteur University, Strassbourg.

Lichtfouse, E., Riolo, J., Albrecht, P., 1990. Occurrence of 2-methyl-, 3-methyl- and 6methyltriaromatic steroid hydrocarbons in geological samples. Tetrahedron Letters 31 (27), 3937-3940.

Lichtfouse, E., Albrecht, P., Béhar, F., 1993. 3-Methyltriaromatic steroids in sediments. Molecular fossils with unknown precursors. In: Garrgiues, P., Lamotte, M. (Eds.), Polycyclic Aromatic Compounds. Taylor and Francis Ltd, pp. 635-638.

Lichtfouse, E., Albrecht, P., Béhar, F., Hayes, J.M., 1994. A molecular and isotopic study of the organic matter from the Paris Basin, France. Geochimica et Cosmochimica Acta 58 (1), 209-221.

Logares, R., Shalchian-Tabrizi, K., Boltovskoy, A., Rengefors, K., 2007. Extensive dinoflagellate phylogenies indicate infrequent marine-freshwater transitions. Molecular Phylogenetics and Evolution 45, 887-903.

Ma, A., Zhang, S., Zhang, D., 2008. Ruthenium-ion-catalyzed oxidation of asphaltenes of heavy oils in Lunnan and Tahe oilfields in Tarim Basin, NW China. Organic Geochemistry 39, 1502-1511.

Matapour, Z., Karlsen, D.A., 2018. Ages of Norwegian oils and bitumen based on agespecific biomarkers. Petroleum Geoscience 24, 92-101.

Moldowan, J.M., Talyzina, N.M., 1998. Biogeochemical evidence for dinoflagellate ancestors in the Early Cambrian. Science 281, 1168-1170.

Moldowan, J.M., Dahl, J., Huizinga, B.J., Fago, F.J., Hickey, L.J., Peakman, T.M., Taylor, D.W., 1994. The molecular fossil record of oleanane and its relation to angiosperms. Science 265, 768-771.

Moldowan, J.M., Dahl, J., Jacobson, S.R., Huizinga, B.J., Fago, F.J., Shetty, R., Watt, D. S., Peters, K.E., 1996. Chemostratigraphic reconstruction of biofacies: Molecular evidence linking cyst-forming dinoflagellates with pre-Triassic ancestors. Geology 24, 159-162.

NIGOGA, 2000. The Norwegian industry guide to organic geochemical analyses. https ://www.npd.no/globalassets/1-npd/regelverk/forskrifter/en/geochemical-analysis. pdf.
Ogbesejana, A.B., 2018. The distributions and geochemical significance of triaromatic steroids and aromatic dinosteroids in crude oils from off-shore Niger Delta Basin, Nigeria. FUPRE Journal of Scientific and Industrial Research 2, 55-70.

Ogbesejana, A.B., Bello, O.M., Uduma, A., 2018. Characterisation of source rocks from off-shore Niger Delta Basin, Nigeria. Journal of Applied Sciences and Environmental Management 22, 356-361.

Penaud, A., Hardy, W., Lambert, C., Marret, F., Masure, E., Servais, T., Siano, R., Wary, M., Mertens, K., 2018. Dinoflagellate fossils: Geological and biological applications. Revue de Micropaléontologie 61, 235-254.

Pollingher, U., 1987. Freshwater ecosystems. In: Taylor, F.J.R. (Ed.), The Biology of Dinoflagellates. Blackwell, pp. 502-529.

Radke, M., Willsch, H., Welte, D.H., 1980. Preparative hydrocarbon group type determination by automated medium pressure liquid chromatography. Analytical Chemistry 52, 406-411.

Rampen, S.W., Schouten, S., Hopmans, E.C., Abbas, B., Noordeloos, A.A.M., van Bleijswijk, J.D.L., Geenevasen, J.A.J., Sinninghe Damsté, J.S., 2009. Diatoms as a source for 4-desmethyl-23,24-dimethyl steroids in sediments and petroleum. Geochimica et Cosmochimica Acta 73, 377-387.

Shetty, R., Stoilov, I., Watt, D.S., Carlson, R.M.K., Fago, F.J., Moldowan, J.M., 1994. Synthesis of biomarkers in fossil fuels: C-23 and C-24 diastereomers of (20R)4,17 $\beta, 23,24$-tetramethyl-18,19-dinorcholesta-1,3,5,7,9,11,13-heptaene. Journal of Organic Chemistry 59, 8203-8208.

Szczerba, M., Rospondek, M.J., 2010. Controls on distributions of methyphenanthrenes in sedimentary rock extracts: Critical evaluation of existing geochemical data from molecular modelling. Organic Geochemistry 41, 1297-1311.

Song, D., Wang, T., Li, M., Ni, Z., 2015. Source of the condensates from the Hetianhe Field and the genetic relationship between the condensates and their associated gases. Science China Earth Sciences 58, 1566-1576.

Summons, R.E., Thomas, J., Maxwell, J.R., Boreham, C.J., 1992. Secular and environmental constraints on the occurrence of dinosterane in sediments. Geochimica et Cosmochimica Acta 56, 2437-2444.

Talyzina, N.M., Moldowan, J.M., Johannisson, A., Fago, F.J., 2000. Affinities of Early Cambrian acritarchs studied by using microscopy, fluorescence flow cytometry and biomarkers. Review of Palaeobotany and Palynology 108, 37-53.

Taylor, F.J.R., 1987. General and marine ecosystems. In: Taylor, F.J.R. (Ed.), The Biology of Dinoflagellates. Blackwell, pp. 399-502.

Thompson, K.F.M., 1983. Classification and thermal history of petroleum based on light hydrocarbons. Geochimica et Cosmochimica Acta 47, 303-316.

Volkman, J.K., 1988. Biological marker compounds as indicators of the depositional environments of petroleum source rocks. In: Fleet, A.J., Kelts, K., Talbot, M.R. (Eds.), Lacustrine petroleum source rocks. Geological Society Special Publication 40, pp. $103-122$.

Volkman, J.K., Barrett, S.M., Dunstan, G.A., Jeffrey, S.W., 1993. Geochemical significance of the occurrence of dinosterol and other 4-methyl sterols in a marine diatom. Organic Geochemistry 20, 7-16.

Wang, Y., Zhang, S., Wang, F., Wang, Z., Zhao, C., Wang, H., Liu, J., Lu, J., Geng, A., Liu, D., 2006. Thermal cracking history by laboratory kinetic simulation of Paleozoic oil in eastern Tarim Basin, NW China, implications for the occurrence of residual oil reservoirs. Organic Geochemistry 37, 1803-1815.

Wang, G., Wang, T.-G., Simoneit, B.R.T., Chin, Z., Zhang, L., Xu, J., 2008. The distribution of molecular fossils derived from dinoflagellates in Paleogene lacustrine sediments (Bohai Basin, China). Organic Geochemistry 39, 1512-1521.

Xiao, H., Li, M., Liu, J., Mao, F., Cheng, D., Yang, Z., 2019. Oil-oil and oil-source rock correlations in the Muglad Basin, Sudan and South Sudan: New insights from molecular markers analyses. Marine and Petroleum Geology 103, 351-365.

Xu, Y., Chang, X., Shi, B., Wang, Y., Li, Y., 2018. Geochemistry of severely biodegraded oils in the Carboniferous volcanic reservoir of the Chepaizi Uplift, Junggar Basin, NW China. Energy Exploration and Exploitation 36, 1461-1481.

Zhang, S., Moldowan, J.M., Bian, L., Zhang, B., Zhang, L., 2000. Biological and molecular geochemical evidence for dinoflagellate ancestors in the Upper Sinian-Cambrian. Acta Geologica Sinica 74, 740-747.

Zhang, S., Moldowan, J.M., Li, M., Bian, L., Zhang, B., Wang, F., He, Z., Wang, D., 2002a. The abnormal distribution of the molecular fossils in the pre-Cambrian and Cambrian: its biological significance. Science in China Series D - Earth Sciences 45, 193-200.

Zhang, S., Liang, D., Li, M., Xiao, Z., He, Z., 2002b. Molecular fossils and oil-source rock correlations in Tarim Basin, NW China. Chinese Science Bulletin 47 Supp, 20-27.

Zhang, S., Moldowan, J.M., Bian, L., Zhang, B., Zhang, L., 2010. Biological and molecular geochemical evidence for dinoflagellate ancestors in the Upper Sinian-Cambrian. Acta Geologica Sinica 74, 740-747. 